\title{
REVISED PROCESS FOR WORK ZONE DECISION MAKING BASED ON QUANTITATIVE PERFORMANCE MEASURES
}

\author{
A Thesis \\ by \\ THOMAS WAYNE HARTMANN
}

\author{
Submitted to the Office of Graduate Studies of \\ Texas A\&M University \\ in partial fulfillment of the requirements for the degree of \\ MASTER OF SCIENCE
}

August 2008

Major Subject: Civil Engineering 


\title{
REVISED PROCESS FOR WORK ZONE DECISION MAKING BASED ON QUANTITATIVE PERFORMANCE MEASURES
}

\author{
A Thesis \\ by \\ THOMAS WAYNE HARTMANN
}

\author{
Submitted to the Office of Graduate Studies of \\ Texas A\&M University \\ in partial fulfillment of the requirements for the degree of \\ MASTER OF SCIENCE
}

Approved by:

Chair of Committee, H. Gene Hawkins Jr.

Committee Members, Timothy J. Lomax

Gerald L. Ullman

Yunlong Zhang

Head of Department, David V. Rosowsky

August 2008

Major Subject: Civil Engineering 


\begin{abstract}
Revised Process for Work Zone Decision Making Based on Quantitative Performance Measures. (August 2008) Thomas Wayne Hartmann, B.S., Texas A\&M University Chair of Advisory Committee: Dr. H. Gene Hawkins, Jr.
\end{abstract}

Work zones create one of the most challenging environments for drivers. Implementing work zones on urban freeways creates many issues, especially with respect to mobility. Decisions made regarding the work zone should be informed by quantitative data, collected in work zones, to ensure that the mobility impacts of the work zone treatments implemented are mitigated. A new decision-making process, which addresses the shortcomings in the current decision-making processes, was developed through the course of this research. The new process incorporates a Performance Measure/Treatment matrix, which recommends multiple performance measures, each of which is chosen to measure the mobility impacts particular to a specific work zone implementation. Most importantly, the revised decision-making process incorporates a feedback loop. Quantitative data collected in work zones is analyzed after the work zone is complete, to determine the impacts specific decisions had on mobility in the work zone. The lessons learned in previous work zones are then incorporated into the decision-making process, lessening the mobility impacts of future work zones. This thesis develops the new decision-making process, and examines the issues with the application of the process. 


\section{DEDICATION}

This thesis is dedicated to my parents, Wayne and Judy, my brother Kenny, the rest of my family, and all of my friends who have supported me. 


\section{ACKNOWLEDGEMENTS}

This thesis would not have seen completion without the assistance of many people. I would like to thank my committee chair, Dr. Hawkins, and my committee members, Dr. Ullman, Dr. Zhang, and Dr. Lomax, for their guidance and support throughout the course of this research.

Thanks also go to my friends and colleagues at the Texas Transportation Institute and Texas A\&M University for making my time working there a pleasure. I would also like to thank the Texas A\&M chapter of the Institute of Transportation Engineers for all the wonderful events and camaraderie.

I would like to extend special thanks to Brad Miller of the Texas Department of Transportation, who was invaluable in helping procure the necessary data.

I would like to thank all of my friends and roommates, for giving me something to do besides study.

Finally, thanks to my father, mother, and brother for their encouragement and support. 


\section{NOMENCLATURE}

$\begin{array}{ll}\text { AASHTO } & \text { American Association of State Highway and Transportation } \\ \text { CMS } & \text { Officials } \\ \text { D } & \text { Changeable Message Sign } \\ \text { DMS } & \text { Distance } \\ \text { DOT } & \text { Dynamic Message Sign } \\ \text { FMCW } & \text { Department of Transportation } \\ \text { HCM } & \text { Frequency Modulated Continuous Wave } \\ \text { ITS } & \text { Highway Capacity Manual } \\ \text { K } & \text { Intelligent Transportation System } \\ \text { LOS } & \text { Density } \\ \text { MPH } & \text { Level of Service } \\ \text { MUTCD } & \text { Miles per hour } \\ \text { O } & \text { Manual on Uniform Traffic Control Devices } \\ \text { PCMS } & \text { Occupancy } \\ \text { TTI } & \text { Portable Changeable Message Signs } \\ \text { TxDOT } & \text { Texas Transportation Institute } \\ \text { TxMUTCD } & \text { Texas Department of Transportation } \\ \text { Q } & \text { Texas Manual on Uniform Traffic Control Devices } \\ \text { U } & \text { Volume } \\ \text { V } & \text { Vehicle Miles Traveled } \\ \text { VPH } & \text { Vecity } \\ \text { VMicles per Hour }\end{array}$




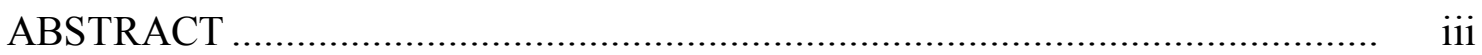

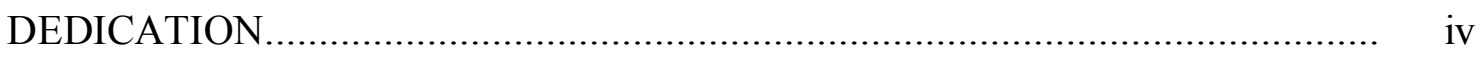

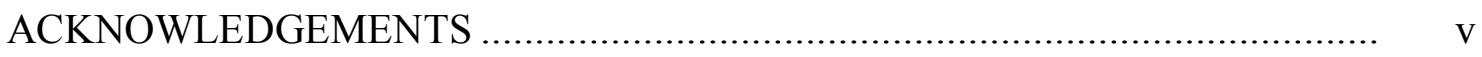

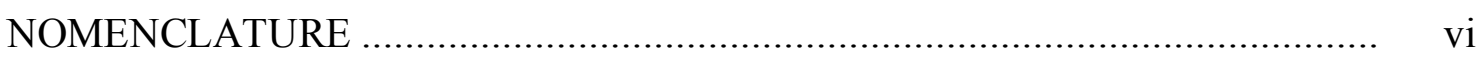

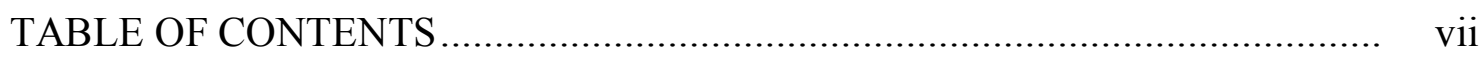

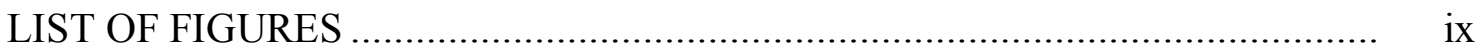

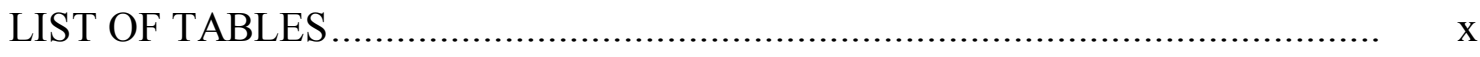

\section{CHAPTER}

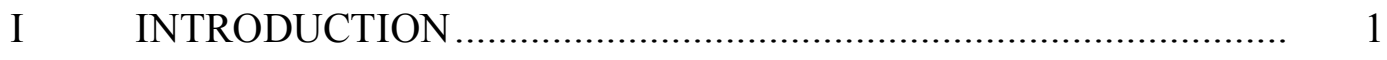

Problem Statement ...................................................................... 2

Objectives............................................................................ 4

Focus of Thesis...........................................................................

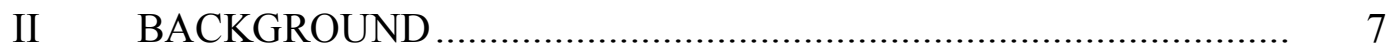

What Are Performance Measures? .................................................... 7

Current Decision-Making Processes ................................................... 9

Issues with Performance Measures in Transportation Engineering ..... 15

Current Monitoring Practices ............................................................. 17

III DEVELOPMENT OF REVISED PROCESS .................................... 20

Geometric Implementation Strategies ............................................. 21

Temporal Implementation Strategies................................................. 22

Information Implementation Strategies ………………………........ 23

Performance Measures............................................................... 25

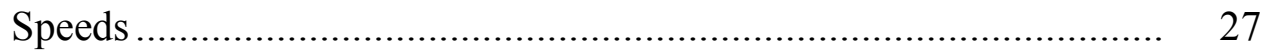

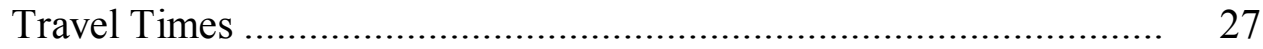

Delays …….................................................................. 30

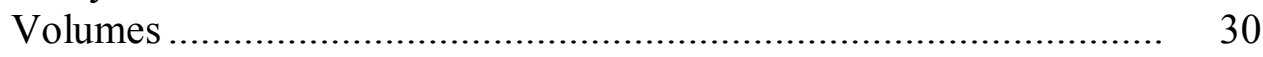


CHAPTER Page

Capacities ............................................................................... 31

Densities.................................................................... 32

Queues .......................................................................... 32

Performance Measure/Treatment Matrix ................................... 35

Revised Decision-Making Process .............................................. 36

IV APPLICATION OF REVISED PROCESS AND ISSUES THEREIN 43

Goals of Analysis ........................................................... 46

Issues with Data.................................................................. 48

Baseline Conditions ............................................................. 50

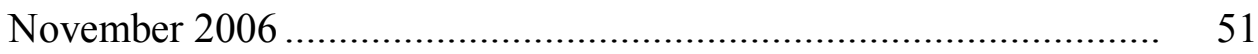

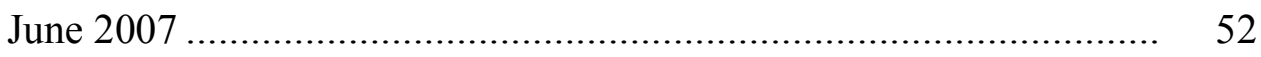

V CONCLUSIONS AND RECOMMENDATIONS ..................... 55

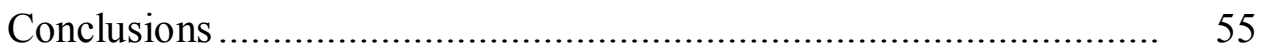

Recommendations ............................................................... 57

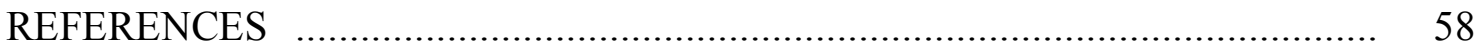

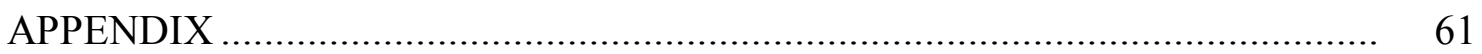

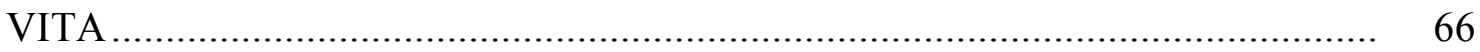




\section{LIST OF FIGURES}

Page

Figure 1 Example 1 of Current Work Zone Monitoring Process

Figure 2 Example 2 of Current Work Zone Monitoring Process .................. 11

Figure 3 Example 3 of Current Work Zone Monitoring Process ................ 12

Figure $4 \quad$ Buffer Index Example ....................................................... 29

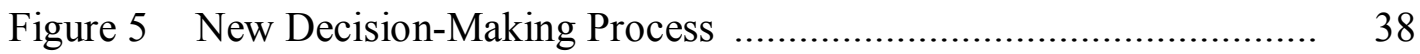

Figure $6 \quad$ Extents of Work Zone ................................................... 44

Figure $7 \quad$ Relevant Portion of Process ...................................................... 47 


\section{LIST OF TABLES}

Page

Table 1 Summary of State Practices........................................................... 17

Table 2 Implementation Strategy Impact Summary .................................... 24

Table 3 Summary Table of Performance Measures ....................................... 33

Table $4 \quad$ Performance Measure/Treatment Matrix .......................................... 34

Table 5 Baseline Performance Measure Summary ....................................... 51

Table 6 Summary of November 2006 Performance Measures........................ 52

Table 7 Summary of June 2007 Performance Measures ................................. 53 


\section{CHAPTER I}

\section{INTRODUCTION}

The creation of the Dwight D. Eisenhower Interstate Highway System after World War II ushered in an unprecedented era of mobility for the public. By facilitating fast, safe, and reliable travel, the national economy was allowed to grow exponentially and the United States rose to its current superpower status. Interstates are the backbone of the communities they pass through, with high development density along the right of way and high traffic volumes on the freeways. The Interstates are nearing the end of their design life. The increasing amount of rehabilitation and expansion needed on these already busy roadways is exposing many more motorists to work zones.

Work zones are one of the most challenging conditions facing drivers. Because agencies have a responsibility to provide safe and efficient roadways, even during times of construction, it is necessary to measure the safety and mobility impacts of work zones, and to use these performance measures to make decisions that will mitigate the potential negative impacts of the work zones. This thesis formulates, describes, and tests a new process to use when making decisions pertaining to work zones, which includes performance measures that will facilitate comparisons and assessments of the operational impacts of various work zone treatments.

This thesis follows the style of Transportation Research Record. 


\section{Problem Statement}

The current process for making work zone related decisions has been developed through decades of application and refinement. While the process is still viable and applicable, it has some deficiencies. The lack of feedback results in an assumption that decisions made in the planning stages will affect mobility in precisely the manner predicted. This assumption results in decision makers choosing implementation strategies regarding traffic control and management that are not adequately monitored in a way that fully quantifies the mobility impacts imposed on road users by the implemented work zone. Currently, some monitoring occurs, mostly utilizing qualitative data to make reactive decisions. Using quantifiable data collected in work zones, rather than a qualitative assessment of what "worked" and what "didn't work," will improve the standards and approaches used to make decisions about work zones. Incorporating feedback into the process will also allow agencies to track how well they are meeting their own goals and policies.

Traffic engineering, more so than any other engineering discipline, addresses a complex mixture of objectives that may be in conflict with each other. Columns in a structure are not designed to experience failure twice a day, while still supporting the building during the other 22 hours. The force of gravity acting on the structure is constant, and the loading can be predicted with relative certainty. In contrast, freeways in most urban freeways experience unacceptable conditions during both morning and afternoon peak times. Other engineering disciplines also do not have the human element inherent to traffic engineering. The human element ensures that no matter how well a facility is designed with respect to mobility or safety, unpredictable driver behavior can cause catastrophic events during the peak period. This complexity necessitates that more than one performance measure be considered when designing and implementing a work zone.

The current process needs to be updated to reflect the complexity of implementing a work zone on an urban freeway. Instead of focusing on a single 
performance measure during the design and implementation of a work zone, multiple performance measures, reflecting considerations across the whole spectrum of the work zone's impacts, from safety and mobility, to environmental impacts, to the impact on the overall traffic network. These measures need to be monitored throughout the life span of the project, not only during the planning phase. The appropriate performance measures for different implementations needs to be determined. For example, target speeds may be an effective performance measure, one that is easily employed for a variety of work zone configurations. In some cases, it may not be descriptive enough of the conditions within the work zone to be of use in decision making. The appropriate measures for each treatment need to be determined in order to ensure that the most useful data is available to make the most informed decisions possible. These measures also need to be constructed in such a way that they are easily comparable across a variety of work zone implementations, in order to facilitate a comparison of the various operational effects of work zones. In short, a new process is needed, one in which multiple, appropriate performance measures are incorporated before, during, and after a work zone's implementation. These performance measures would be used to make decisions that would further improve the performance, especially the safety and mobility, in work zones on urban freeways. 


\section{Objectives}

The objectives of this thesis were two-fold:

1. Propose a process to relate work zone planning decisions and potential work zone performance measures

The new process incorporates multiple work zone performance measures throughout the life cycle of the work zone. Multiple performance measures are needed in work zones, because a single performance measure does not adequately address the innate complexity of a work zone. The complex relationship between work zone implementation strategies and the impacts on safety and mobility necessitates the use of multiple performance measures to make decisions. As part of the framework, a matrix indicating the appropriate performance measures to use for various work zone treatments was developed.

\section{Determine a set of performance measures that would enable comparison} of the mobility impacts of various work zones.

Work zones are currently modeled at the project level and at the agency level. At the project level, performance measures such as queue lengths and travel times through the work zone are collected to assess the traffic impacts of the implemented work zone. The project level can be considered a small-scale assessment of work zone impacts. At the agency level, broad statistics such as total work zone exposure for an area are compiled to give an overview of the agency's total work zone activity. The aggregated overview can be considered the large-scale assessment of work zone impacts. What is currently missing is a way for agencies to compare the performance of several work zones, an intermediate level of analysis. Performance measures were proposed that will 
be applicable at both the small-scale and large-scale levels. These measures will enable decision makers to compare the impacts of many implemented work zones.

In order to complete these objectives, many different activities were necessary. Background information relevant to the development of the new decision-making framework, was compiled, including the performance measures utilized therein. Other previous research on mobility performance measures, apropos to work zones, was also summarized.

Possible treatments that could be used in a work zone on an urban freeway, and the mobility impacts they could create, were identified. The treatments were compiled from the AASHTO's “A Policy on Geometric Design of Highways and Streets” (also known as the "Green Book"), as well as from interviews with transportation engineers. Performance measures that could be used to assess the mobility impacts of the implemented work zone treatments were compiled and devised. The measures were assessed for their practicality, their applicability over multiple work zones, and their overall usefulness. The performance measures were then assigned to the appropriate work zone treatments, in order to recommend the most descriptive measures to use for assorted work zone implementation strategies. The result was a Performance Measure/Treatment Matrix that can be used to choose the most appropriate performance measures to compare the mobility impacts of various work zones.

A new decision-making process was created, incorporating the Performance Measure/Treatment Matrix. This new process integrates various performance measures into the decision-making process, throughout the lifecycle of a specific work zone implementation. While the current process is an effective reactive tool for decision making in work zones, a new model is needed that will enable proactive decisions to be made that will improve mobility in work zones. The revised process addresses the identified shortcomings in the existing processes.

The process was then applied to data collected in a work zone to illustrate how it can be used to assess decisions made in a work zone. The data analysis focused on the post-hoc analysis and feedback portion of the revised process. The results of the data 
analysis were used to demonstrate the use of the new process, as well as some of the inherent difficulties in monitoring and analyzing decisions in a work zone.

\section{Focus of Thesis}

This thesis focused on performance measures describing mobility on urban freeways. Urban areas are defined as "those places within boundaries set by the responsible State and local officials having a population of 5000 or more (1)." The four urban roadway system classifications are principal arterial, minor arterial, collector, and local. Principal arterials include interstates, freeways, and other arterials, which may have little or no access control. Principal arterials are primarily concerned with mobility, and therefore typically have very few access points. These facilities are "unusually significant" because they constitute a high proportion of total urban travel, even though consist of a relatively small percentage of total lane miles in urban areas (1).

Due to the high traffic volumes, high speeds, emphasis on mobility, and overall importance to the urban road network, urban principal arterials (specifically freeways) were the focus of this thesis. A performance measure that can adequately describe the mobility conditions on a freeway should be adaptable to any of the lower classifications. Due to the emphasis on mobility, work zone impacts on an urban freeway are often much higher than the impacts on a lower classification. Therefore, this thesis's focus on work zones' impact on mobility necessitates a focus on urban principal arterials. 


\section{CHAPTER II}

\section{BACKGROUND}

In order to develop viable improvements to address the shortcomings of the current framework, some background information is necessary. The following sections describe the current processes for decision making in work zones, as well as some key points to consider when creating a new process.

\section{What Are Performance Measures?}

For the sake of clarity, it is necessary to define the differences between data, performance measures, and decisions. All of these terms are interrelated, and flow from one another. In this thesis, data is defined as the raw information gathered from a work zone; it is what is measured directly from a work zone. Examples of data collected in a work zone could be the speeds of vehicles through the work zone, or the overall volume of vehicles traveling through the work zone for a given time period. The data collected is then used to create a performance measure. The performance measure illustrates some condition of interest in the traffic stream, such as the speed differentials in the work zone or the reduction in overall volumes due to the implementation of the work zone. Using these performance measures, a decision can then be made regarding what should be done to improve conditions. The performance measures can be evaluated to determine whether the work zone is meeting the agency's goals for the work zone. An agency may be concerned about mobility through work zones; one of their goals would be to keep the average throughput above a certain threshold (1500 vehicles per hour, for example). Data, in the form of traffic volumes, would need to be collected in the work zone in question. A performance measure relating to the agency's mobility goals would be the number of vehicles passing through the work zone per hour. Using the collected data, the performance measure (average hourly throughput in the work zone) could be calculated. Based on the performance measure, a decision can be made. Is the average 
throughput observed in the work zone above the 1500 vph threshold set by the agency? If the threshold is exceeded, then no action needs to be taken; the work zone is performing adequately. If the observed average throughput is less that $1500 \mathrm{vph}$, then steps need to be taken to improve the conditions in the work zone so traffic can flow more smoothly. For example, if closing one lane on a four lane, divided urban freeway during the peak period is causing increased congestion and decreased throughput, the agency would use the performance measure generated from observed data to make a decision that the lane should not be closed during the peak period. Opening this lane would add capacity, increasing the throughput through the work zone and bringing the facility into compliance with the agency's goals.

When formulating performance measures, it is of vital importance to ensure that agency goals drive the development of appropriate measures, not the available data. For performance measures to be effective, they must be able to illuminate deficiencies in current practices. By formulating performance measures with an eye towards the ultimate goals for the agency, any standard practice within the agency that is not meeting these goals can be ferreted out and improved. Conversely, if performance measures are created based on the available data, such as data already collected by the agency, the performance measures may not reveal anything new about the conditions on the facility. Measures tailored to existing data have the potential to only describe the existing conditions, not shed new light on previously unnoticed mobility or safety issues.

Performance measures are classified in two distinct categories (6). Output-based performance measures quantify efforts made as part of the project, or steps taken during the project. An example of an output performance measure in a work zone is measuring how many times a safety inspection was performed at the site. These performance measures assume a relationship between performing these steps and the steps causing a favorable effect. Output performance measures offer the benefit of easy data collection, but the actual cause of observed traffic conditions are often not as obvious as the underlying assumption implies. In the example of counting safety inspections performed at the work zone, simply counting the number of inspections performed at a site does not 
improve safety. The measures taken in response to the results of the safety inspections are what actually improve safety in the work zone.

In contrast, outcome-based performance measures describe the observed effects of efforts. These measures indicate whether a particular effort is having the desired effect. A work zone related example of an outcome-based performance measure is the average increase in peak-period delay. Outcome-based measures offer the advantage of describing actual conditions, as opposed assuming that a particular action will lead to a particular outcome. The disadvantage to this approach is increased data requirements. Quantifying conditions in the field requires data to be collected in the field; reducing and analyzing this data requires more time and effort than the output-based measures. It also more difficult to prescribe what effect led to the observed reactions, especially when dealing with traffic conditions in a work zone. The work zone is not a sterile laboratory, where changes are made one at a time in a controlled environment on a uniform population. Decisions are often made on the fly, when needed, and the traffic characteristics vary day to day, even hour to hour. This obfuscates drawing a conclusion that a particular effort led to an observed reaction.

\section{Current Decision-Making Processes}

There is no standard process currently used to make decisions in work zones. Every agency has a different strategy, and many rely solely on engineering judgment to make decisions. Three models of the typical work zone decision-making strategy are shown in Figures 1, 2, and 3. 


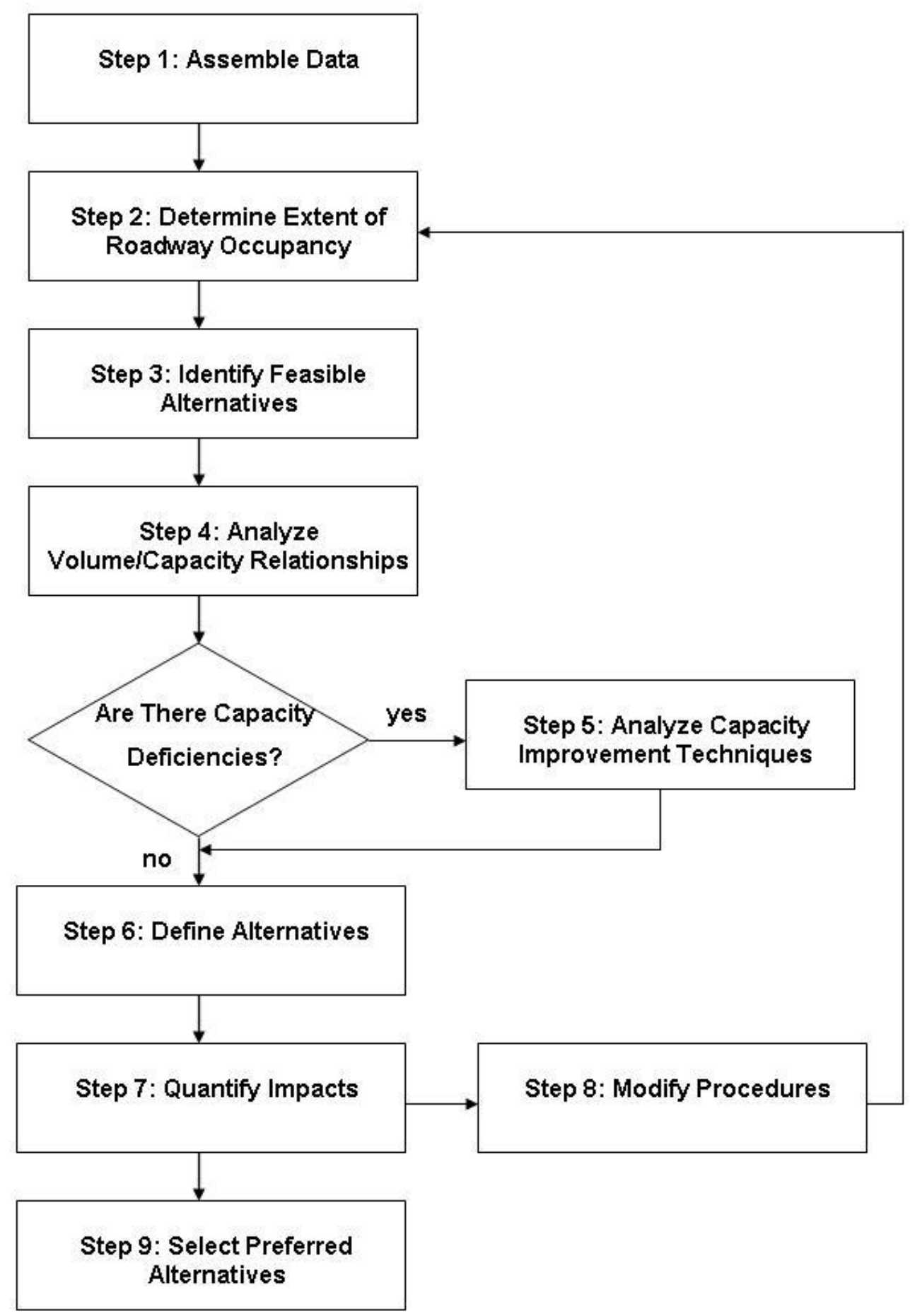

Figure 1: Example 1 of Current Work Zone Monitoring Process (2) 


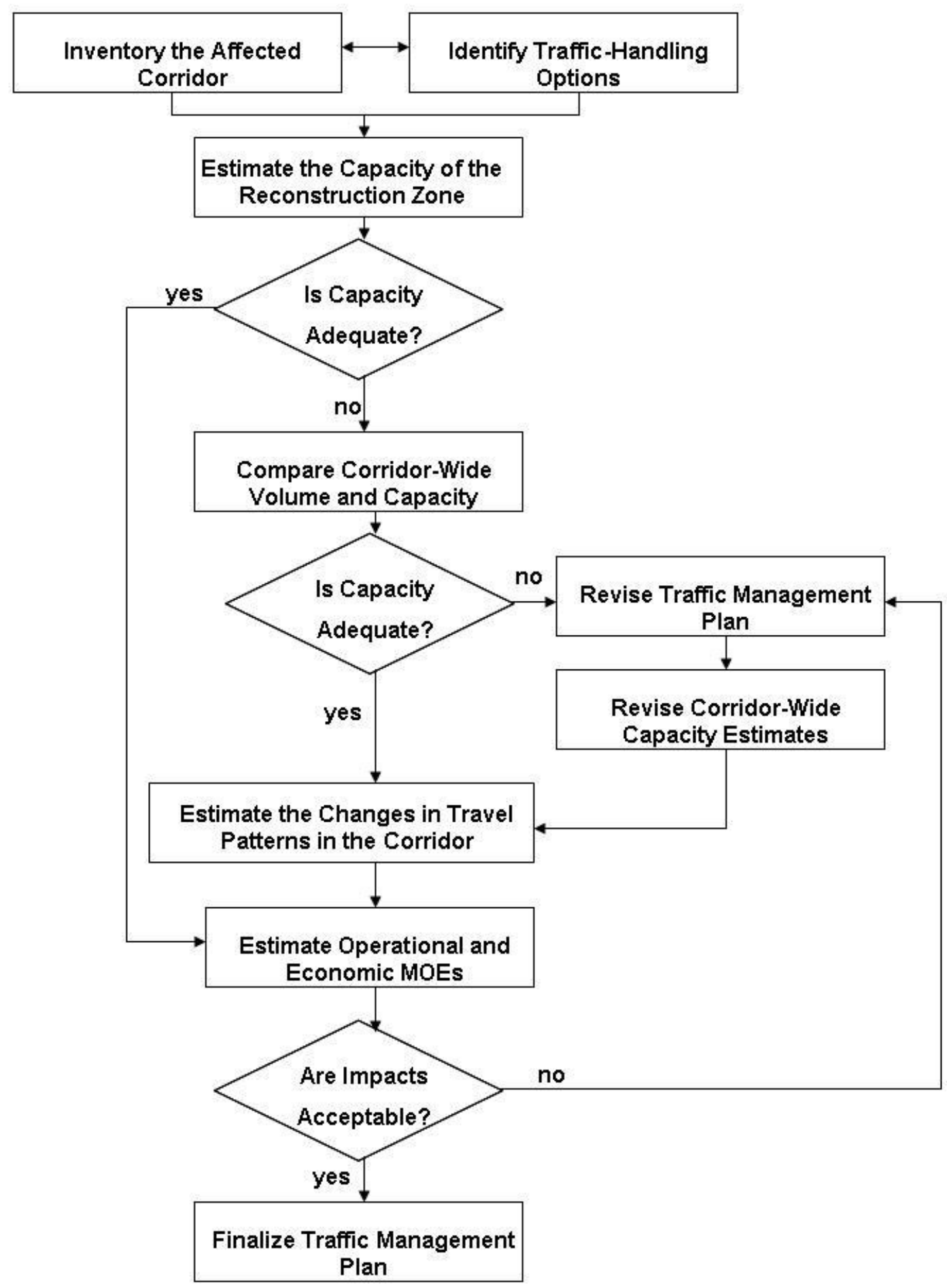

Figure 2: Example 2 of Current Work Zone Monitoring Process (3) 


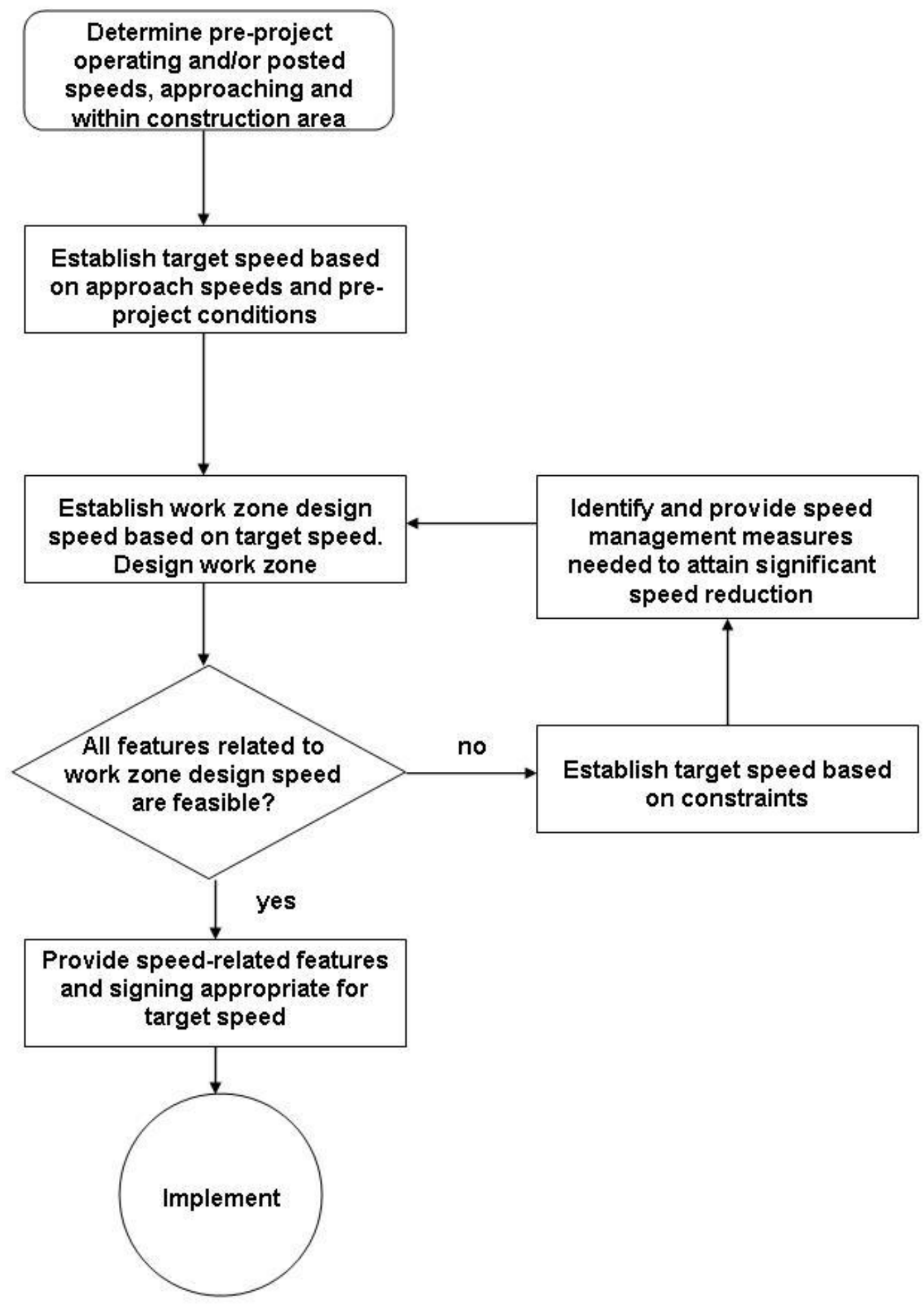

Figure 3: Example 3 of Current Work Zone Monitoring Process (4) 
Despite the variations in the frameworks used for decision making, the current frameworks all have essentially the same structure. Once the need for a work zone is realized, the current conditions on the facility are quantified by collecting data under existing conditions. The data collected depends on the performance measures already specified by the agency. Depending on the conditions already present on the facility, a goal is then set for the conditions on the facility after the work zone is implemented. Alternative work zone configurations and strategies are developed, and then analyzed based on the aforementioned performance measure to determine the operational effects of implementation. If the alternatives all fail to meet acceptable standards, they are revised until they meet these standards. When an acceptable performance is achieved, the alternative with the least undesirable impacts is chosen and implemented. Of course it would be ideal to choose an alternative with the "best" impacts on the traveling public, or the "least" impacts, but when dealing with work zones that almost invariably reduce mobility, it is more realistic to try to minimize that impact than it is to completely eliminate it. It is infeasible to have a work zone with zero impact on the mobility and safety conditions of the facility. As shown in the figures, each of the frameworks has some superficial differences, but they are all essentially the same. Some of the steps may be in a different order, and different performance measures may be used in different frameworks, but they all follow the basic procedure outlined above.

The current process has three basic, underlying flaws. For the most part, analysis of the various alternatives is based on a single performance measure. Traffic engineering, more so than any other engineering discipline, addresses a complex mixture of objectives that may be in conflict with each other. The complex interaction between an assortment of factors, from easily measured engineering considerations such as traffic volumes, to more obtuse factors such as driver satisfaction, is a hallmark of traffic engineering. The human elements inherent in decision making on roadways are a major issue, and may be interpreted differently by different engineers. This complexity necessitates that more than one performance measure be considered when designing and implementing a work zone. 
The over reliance on the same performance measures for every situation is another major flaw in the traditional framework. Work zone treatments are as varied as the roadways they are used on, and each type of treatment impacts the safety and mobility of the roadway in different ways. Appropriate measures should be used for each type of work zone treatment. In many cases, the appropriate performance measures for one treatment will be the appropriate measures for other treatments. But some performance measures that accurately describe the operation of a work zone under one treatment may be unsuitable for another treatment. For example, queue-based performance measures may best describe the impacts of a lane closure, but would not describe the impacts of employing a dynamic message sign to inform drivers to slow down in a work zone. The appropriate measures need to be utilized for various types of treatments. It is also important for the performance measures to be compatible with the overall goals of the agency. One major reason for using performance measures when creating a work zone traffic control plan is to make decisions that will create conditions conducive to desirable operations on the facility; if the performance measures used in a work zone are not compatible with performance measures normally used on the roadway, the proper decisions that would lead to desirable operations may not be made.

The major deficiency in the current decision-making process is the lack of feedback once the work zone is implemented. Currently, some data is collected in active work zones, and some qualitative judgments are made about the mobility and safety throughout the work zone. Crashes occurring within the work zone are noted and reviewed, and any problems with the work zone are rectified in response. Traffic conditions throughout the affected area are monitored, and actions are taken if the performance measures are not satisfactory. The current framework's reactive stance is effective in responding to problems once they occur, but does not effectively describe the overall mobility impacts of an implemented work zone. A mechanism for incorporating the results of work zone implementation standards needs to be introduced into the procedure, so that breakdowns in mobility may be observed and corrected. The standards used by agencies to set up work zones could be improved by addressing 
problems caused by work zones in the design phase, preemptively correcting the issue before it ever occurs. The most practical way to improve the standards would be to use feedback from the field, in work zones that were implemented using the standards. By comparing various work zones, and tracking the mobility trends observed, an agency could assess their standard procedures, and take steps to improve their approach if necessary, as well as improve specific work zones in the field.

\section{Issues with Performance Measures in Transportation Engineering}

Traffic engineering, more so than any other engineering discipline, addresses a complex mixture of objectives that may be in conflict with each other. Most civil engineering issues can be described in absolutes, based on physics. A pipe network may need to be able to transport a minimum volume of water up a hill, or a column in a building may need to be able to support a certain loading. In order to create an adequate pipe network, the hydraulic engineer must break down the problem into the relevant physical constraints, such as the energy head at various points along the system, the number of pumps needed, the flow rate of water through the pipes, and the necessary pipe sizing. When designing structural columns in a building, the structural engineer must consider the static and dynamic loads, the resultant forces within the column, and the physical properties of the column itself. In both of these examples, the problems and design issues can be distilled into basic physics problems. Assuming the calculations were correct, and barring unforeseen damage/deterioration/etc., the designed column will always be able to support the load placed on it, and the pipe network will always be able to move the required amount of water. The straightforward nature of these engineering disciplines allow for straightforward performance measures. The performance measures needed are readily agreed upon, because they are based on unarguable physical laws. In contrast, transportation engineering is not so straightforward. This discipline of civil engineering involves many societal concerns that are not an issue in other civil engineering disciplines, such as hydraulic or structural 
engineering. Because of the sheer volume of citizens who are dependent on the transportation system for their very way of life, for everything from their occupations to their leisure activities to their necessary consumer activities, the societal implications of transportation engineering decisions must be weighed heavily. The complex societal costs of any decision that could potentially impact operations on a facility (increased traveler costs, lost productivity, increased emissions due to congestion, etc.) must be included in any performance measures, along with the more obvious consequences (throughput volumes, average speeds, average crash rates, etc.). Consideration must also be given to the fact that work zones, by nature, are temporary conditions on the facility. Complete avoidance of traffic impacts is often not feasible within the constraints of a project (budget, space issues, project timelines, etc.). Engineers must balance the chosen performance measures in a way that is most conducive to the public good, within the given constraints. Certain choices could greatly alleviate the impacts of the work zone, such as constructing an alternate route on a new alignment while the existing facility is under construction, but would not be the best use of public money, infrastructure, and resources. The corrections necessary to address the impacts of a work zone may be too permanent to be appropriate, because the conditions caused by the work zone only exist as long as the work zone is in place. For example, restriping lanes, retiming signals in the area, or changing alignments may address the impacts of the work zone, but would not be necessary once the work is complete. The temporary nature of work zones also influences the choice of performance measures, specifically with regards to data requirements. If too much data is required to calculate a performance measure, the project may be finished by the time a decision is made to correct an observed problem. Ultimately, the decision of which performance measures are needed to assess conditions on a facility is dependent on the goals of the agency responsible for the facility, as well as the constraints of the project. 


\section{Current Monitoring Practices}

In addition to predicting the capacities available in work zones, and the resulting traffic impacts, state DOTs use a variety of mobility-related performance measures in the existing work zone to monitor the actual traffic impacts. In late 2005, a survey of state agencies around the country was administered to determine what, if any, performance measures were used to monitor traffic impacts in implemented work zones (5). The results of this survey are presented in Table 1.

Table 1: Summary of State Practices

\begin{tabular}{|c|c|c|c|}
\hline $\begin{array}{l}\text { Performance } \\
\text { Measure }\end{array}$ & States Using Metric & Threshold Measurement & Measurement Method \\
\hline \multirow{13}{*}{ Time Delay } & Arizona DOT & 10 minutes & License plate reader \\
\hline & $\begin{array}{l}\text { Arkansas State Highway } \\
\text { and Transportation } \\
\text { Department }\end{array}$ & $\begin{array}{l}\text { Inform drivers of any } \\
\text { impending delays so alternate } \\
\text { route could be chosen }\end{array}$ & $\begin{array}{l}\text { Automatic Work Zone } \\
\text { Information System, DMS }\end{array}$ \\
\hline & California DOT & 30 minutes & AWIS, calculations \\
\hline & Indiana DOT & 10 minutes & $\begin{array}{l}\text { Projected using } \\
\text { manual, past experience }\end{array}$ \\
\hline & Louisiana DOTD & 30 minutes & Measured in field \\
\hline & Maine DOT & 5 minutes & \\
\hline & Maryland DOT & 8 minutes & $\begin{array}{l}\text { Traffic Control Manager in } \\
\text { field }\end{array}$ \\
\hline & Massachusetts DOT & 12 minutes & Projected using modeling \\
\hline & Missouri DOT & 5 minutes & Measured in field \\
\hline & North Dakota DOT & 15 minutes & \\
\hline & South Dakota DOT & $10-15$ minutes & $\begin{array}{l}\text { Projected using } \\
\text { computer simulation }\end{array}$ \\
\hline & Wisconsin DOT & 30 minutes & Projected in design phase \\
\hline & Wyoming DOT & 20 minutes & Projected using modeling \\
\hline \multirow{7}{*}{ Queue Length } & Arizona DOT & Manage queue lengths & On-site Inspectors \\
\hline & Indiana DOT & 1 mile & $\begin{array}{l}\text { Projected using } \\
\text { manual, past experience }\end{array}$ \\
\hline & $\begin{array}{l}\text { Kentucky Transportation } \\
\text { Cabinet }\end{array}$ & Minimum queue length & $\begin{array}{l}\text { Projected using QuickZone, } \\
\text { some work zones inspected }\end{array}$ \\
\hline & Maryland DOT & $1 / 2$ mile & On-site Inspectors \\
\hline & North Carolina DOT & 2 miles & Projected in design phase \\
\hline & Tennessee DOT & Manage queue lengths & Projected in design phase \\
\hline & Wisconsin DOT & $2-3$ miles & Projected in design phase \\
\hline \multirow{3}{*}{ Traffic Volumes } & New Hampshire DOT & 1500 pcplph & Police \\
\hline & New York State DOT & LOS E & Projected in design phase \\
\hline & Ohio DOT & No set goals & Automatic Traffic Recorder \\
\hline
\end{tabular}


The survey found that while many states are concerned with the mobility impacts of work zones, most do not specifically monitor those impacts once the work zone is implemented. Most of the performance measures used to mitigate congestion are implemented in the design and planning stages. The performance measures' thresholds are often arbitrary, and may not reflect existing conditions on the roadway. For example, Maryland DOT's performance measure of a $1 / 2$ mile queue length would not accurately describe the impact of the work zone if queues on the roadway already regularly exceeded $1 / 2$ mile.

In order to gauge the state of the practice within the Texas Department of Transportation, the author performed a telephone survey of a representative sample of districts (7). Seven of the 25 TxDOT districts were surveyed to determine what performance measures are currently being used to monitor mobility in work zones. The districts were intended to provide a representative cross-section of districts in Texas, with respect to geographic location, level of urbanization, and population. Respondents were involved in both the planning and implementation stages of the work zone process. The survey found that TxDOT doesn't put a significant emphasis on analyzing performance measures as a part of the decision-making process. The general approach to work zones for the districts interviewed seems to be to set up work zones based on TxDOT standards, previous successes, and engineering judgment and assume that it will work, because it has worked in the past. The extent of formal monitoring that is currently performed consists of a traffic control device survey performed every two weeks as dictated by TxDOT, and safety reviews of accidents that occur in work zones. Based on the results of these surveys, performance monitoring in work zones is currently a somewhat qualitative endeavor, with changes only occurring when there seems to be a problem. One qualitative measure that was repeatedly mentioned by respondents was the number of complaint phone calls received. If a number (three calls was given by a rural district as a rough estimate) of citizens call and complain about a particular work zone, it is a sign that something is wrong and the work zone needs to be reevaluated. 
Decision makers do seem to care about performance measures for work zones in a qualitative sense, but do not feel the need for a formal, quantitative set of measures to tell them what they already feel they intuitively know.

While decision-makers may not feel that quantitative measures are necessary, they can be useful to either prove or disprove their intuition. If the performance measures verify the assumptions held about the mobility impacts of various decisions, then there is no need to revise the agency's standards. However, if the data contradicts the commonly held assumptions, then the information gleaned can be used to revise the standards and approaches to improve future work zone implementations. In order to learn the correct lessons from an implemented work zone, the appropriate performance measures must be used in the analysis. 


\section{CHAPTER III}

\section{DEVELOPMENT OF REVISED PROCESS}

In order to develop the Performance Measure/Treatment Matrix, a key component of the new decision-making process, it was necessary to determine both the possible work zone treatments and the appropriate performance measures to measure the impacts of these implementations.

While each work zone is a unique byproduct of the facility it is placed on, there are certain treatments which are common options for every work zone implemented on an urban freeway. Potential work zone treatments were determined from various sources, including state DOTs (5), the AASHTO Policy on Geometric Design of Highways and Streets (1), and the Manual on Uniform Traffic Control Devices (9). The anticipated impacts caused by the work zone were used as the basis for deciding which performance measures were most appropriate for the various work zone treatments.

There are many treatment strategies currently in use in work zones on urban freeways, but few significantly impact mobility in the work zone. Some strategies, such as altering pavement markings and increasing signage, are widely used but have very little impact on mobility. Treatments with significant impact the mobility on a freeway can be considered in terms of geometric, temporal, and informational implementation strategies. 


\section{Geometric Implementation Strategies}

The most commonly used geometric implementations that affect mobility are lane shifts, lane constrictions, and lane closures. Lane shifts are commonly utilized when work is necessary on the shoulder, but the shoulder alone does not provide enough space for the work to be done. Lane shifts may also be used when the paved surface is wide enough to accommodate shifting lanes into the shoulder area in order to allow work to be done in a main lane. By introducing a deflection into the normal driving patterns of the freeway, a lane shift changes the mobility of the freeway. This change is most readily apparent, and most measurable, through speeds in the work zone.

Lane constrictions are an option when work must be done on an edge of the freeway, but the required space does not infringe on the traveled way enough to warrant a lane shift. The TxMUTCD allows lane constrictions when work is performed on the shoulder, with minor lane encroachment, as long as the lanes remain at least 10 feet wide (9). Constricting the width of lanes on an urban freeway affects both speed and capacity.

Lane closures have a far more significant impact on the mobility of a roadway undergoing a significant, long-term work zone project. Closing one or more lanes drastically impacts the capacity of the roadway, in turn affecting the speeds and volumes possible through the closed section. Reducing the number of open lanes causes many conditions which serve to reduce the capacity in a section. The impacts of lane closures are most readily apparent through queuing, slower speeds, reduced volumes, and a host of other related mobility issues. 


\section{Temporal Implementation Strategies}

When a treatment is utilized is often as important as what treatment is chosen. These decisions are typically only necessary when one or more lanes must be closed in order to complete the project. When scheduling a major work zone project, the practitioner must decide between:

- $\quad$ Partial closure vs. full closure;

- $\quad$ Nighttime work vs. daytime work;

- Weekend work vs. weekday work; and/or

- $\quad$ Peak vs. off-peak.

The decision between partial closure and full closure involves many tradeoffs. Fully closing a facility enables work to be done throughout the entire section, with no conflict between workers and motorists. This allows for a very compressed work schedule, but completely removes the capacity of the facility from the traffic network. Closing one or more lanes, while leaving one lane open to serve traffic, greatly extends the timeframe for the work being done, and exposes both drivers and workers to increased safety risks. However, only partially closing a lane allows at least some mobility (however reduced) to be maintained throughout the duration of the project.

The other temporal decisions are a choice between closing a facility when traffic demand is much lower, such as nights or off-peak, but worker costs and job complexity is higher, or when demand is higher, but costs and complexity are reduced, i.e. days and peak times. Working at night allows for lesser mobility impacts, because the travel demand on the freeway is much less. Restricting lane closures to time periods with reduced demand lessens the impact on mobility, but increases costs (through overtime, extended time necessary to complete the project, illumination costs, etc.). Closing lanes during periods of heavy demand, such as peak hours or weekdays, shortens the time frame of the project and reduces the cost, but impacts mobility more and exposes drivers 
and workers to more safety hazards. The consequences of these decisions must be heavily weighed.

Informational Implementation Strategies

Informational implementation strategies, specifically the use of changeable message signs (CMS) or dynamic message signs (DMS), can be a valuable tool for increasing drivers' awareness of the impacts of work zones. Message signs can serve two main purposes: they can simply inform drivers (i.e. upstream lane closures), or about observed conditions (when linked to real-time data collected in the work zone). They can also be used to divert traffic, in cases when mobility through the work zone breaks down (due to work zone impacts or non-recurrent congestion, such as collisions) or when the facility is completely closed downstream of the message signs. Informing motorists can reduce turbulence in the traffic stream caused by driver uncertainty, and reduce demand by diverting traffic before it enters the congested area. Table 2 summarizes the significant mobility aspects impacted by each treatment strategy. 
Table 2: Implementation Strategy Impact Summary

\begin{tabular}{|c|c|c|c|c|c|c|c|c|c|}
\hline & \multicolumn{8}{|c|}{ Mobility-Related Impacts Expected Under Strategy } \\
\hline & & Speeds & $\begin{array}{l}\text { Travel } \\
\text { Times }\end{array}$ & Delays & Volumes & Capacities & Densities & Queues & $\begin{array}{c}\text { Project } \\
\text { Duration }\end{array}$ \\
\hline \multirow{3}{*}{$\begin{array}{c}\text { Geometric } \\
\text { Implementation } \\
\text { Strategies }\end{array}$} & Lane Shifts & $\mathbf{X}$ & $\mathbf{X}$ & $\mathbf{X}$ & & & & & \\
\hline & $\begin{array}{c}\text { Lane } \\
\text { Constrictions }\end{array}$ & $\mathbf{X}$ & $\mathbf{X}$ & $\mathbf{X}$ & & $\mathbf{X}$ & & & \\
\hline & $\begin{array}{c}\text { Lane } \\
\text { Closures }\end{array}$ & $\mathbf{X}$ & $\mathbf{X}$ & $\mathbf{X}$ & & $\mathbf{X}$ & $\mathbf{X}$ & $\mathbf{X}$ & \\
\hline \multirow{4}{*}{$\begin{array}{c}\text { Temporal } \\
\text { Implementation } \\
\text { Strategies }\end{array}$} & $\begin{array}{l}\text { Partial vs. } \\
\text { Full Closure }\end{array}$ & $\mathbf{X}$ & $\mathbf{X}$ & $\mathbf{X}$ & & $\mathbf{X}$ & & $\mathbf{X}$ & $\mathbf{X}$ \\
\hline & $\begin{array}{l}\text { Nighttime vs. } \\
\text { Daytime }\end{array}$ & & $\mathbf{X}$ & $\mathbf{X}$ & $\mathbf{X}$ & & $\mathbf{X}$ & & $\mathbf{X}$ \\
\hline & $\begin{array}{l}\text { Weekend vs. } \\
\text { Weekday }\end{array}$ & & $\mathbf{X}$ & $\mathbf{X}$ & $\mathbf{X}$ & & $\mathbf{X}$ & & $\mathbf{X}$ \\
\hline & $\begin{array}{l}\text { Peak vs. Off- } \\
\text { Peak }\end{array}$ & & $\mathbf{X}$ & $\mathbf{X}$ & $\mathbf{X}$ & & $\mathbf{X}$ & & $\mathbf{X}$ \\
\hline \multirow{2}{*}{$\begin{array}{l}\text { Informational } \\
\text { Implementation } \\
\text { Strategies }\end{array}$} & $\begin{array}{c}\text { Informative } \\
\text { Messages }\end{array}$ & & $\mathbf{X}$ & $\mathbf{X}$ & $\mathbf{X}$ & & & $\mathbf{X}$ & \\
\hline & $\begin{array}{c}\text { Diversionary } \\
\text { Messages }\end{array}$ & & $\mathbf{X}$ & $\mathbf{X}$ & $\mathbf{X}$ & & & $\mathbf{X}$ & \\
\hline
\end{tabular}




\section{Performance Measures}

Measuring the mobility impacts of different implementation strategies requires performance measures that can describe the various aspects of mobility. At the macroscopic level, the performance of the traffic stream as a unit is measured through averages or aggregated measures (10). This level of measurement is appropriate for large-scale, long term level analysis. The large-scale perspective is vital in obtaining a comprehensive overview of traffic conditions for large geographic areas, such as a whole freeway or an entire network. Microscopic performance measures describe mobility as a function of the subject vehicle's interactions with the vehicles leading, following, and flanking it (10). These performance measures are appropriate for short-term, small scale analysis.

In some cases, neither large-scale nor small-scale measures may be appropriate to describe the conditions an engineer is trying to ascertain. Work zones present such a situation. Work zones do not fit neatly into either large-scale or small-scale measures. By nature, work zones are temporary, unlike the permanent network described by largescale categories. Large-scale measures, such as the buffer index, are often too broad to specifically address the impacts of only the work zone. These measures illustrate the overall performance of a corridor, or network, over long periods of time. However, work zones are typically a small portion of a corridor, or a facility, with much shorter life spans than the facilities they are implemented on.

Small-scale measures are useful when describing the day-to-day operation of work zones. The work zone likely has many different geometric, temporal, and signing configurations throughout the project, so such small-scale measures may inaccurately portray the nature of the work zone's impact on mobility. Multiple performance measures are needed to completely describe the impacts of the work zone than are needed under normal conditions on the same freeway, due to the complex and unavoidable impacts the work zone has on the freeway. Amalgamated measures are needed to supplement the existing small-scale measures to develop a clearer vision of the 
impacts a work zone has on a facility. By combining these point measurements over the length of the work zone, but not the entire roadway, the intermediate impacts of the work zone implementation can be determined and mitigated, if necessary.

When formulating performance measures, special care must be taken to ensure that goals drive the performance measures, so that performance can be improved. When performance measures drive goals, the goals have a propensity to reflect the current conditions in order to make the existing performance measures look good, which rather than improving conditions, rewards sub-par performance. There is also an issue with making absolute thresholds for performance measures. For example, a performance measure would be absolute in the sense that $1500 \mathrm{vph}$ is the cut off for acceptable service. Once the volume observed on the freeway reaches $1501 \mathrm{vph}$, the mobility does not instantaneously fall off to an unacceptable level. This fuzziness and uncertainty in the making decisions based on performance measures formulated from the relatively limited data available in a work zone must be taken into account.

Amalgamated measures are needed to supplement the small-scale and large-scale measures currently used to measure:

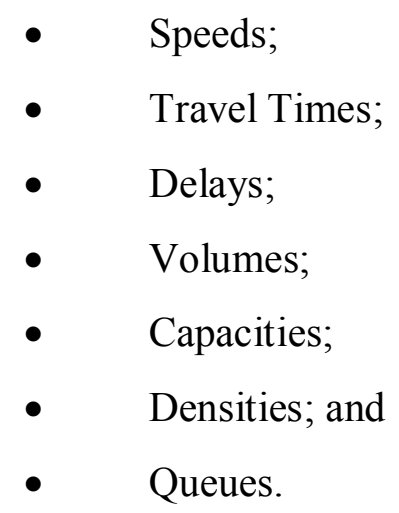

Each of these operational characteristics can be measured and described in a multitude of ways, at all three levels of measurement (small-scale, large-scale, and amalgamated.) There are no absolutely correct performance measures that are applicable to every situation. Every work zone implementation is different, as is the 
facility and network where the work zone is implemented. The nature of the system surrounding the work zone influences the appropriate performance measures. The type of analysis to be conducted, as well as the decisions to be made using the measures, greatly influences which performance measures are appropriate. All of the performance measures are interrelated, and are often available from the same data set. The difficulty comes in determining which performance measures will impart the information necessary to make the best possible decisions in the work zone.

Speeds

The most commonly used small-scale speed measure is average speed at a single location. Average speed at the large-scale level can be measured as a space mean speed or a time mean speed. The difference between large-scale and intermediate speed performance measures is only a question of the level of aggregation. The amalgamated performance measure, to be useful, must treat the traffic through the work zone as a continuous stream and average the individual speeds of the vehicles. An amalgamated measure could be the time mean speeds at various points in the work zone, or average speed through a work zone.

\section{Travel Times}

Increased travel times are the most palpable result of traffic congestion for most drivers. Drivers notice their travel times every time they take a trip. When a work zone is implemented on a freeway, drivers who use the facility every day may not notice a 5 mile an hour change in their average speed, but they will notice the corresponding 5 minute increase in their commute. In addition to the travel time itself, drivers also care about travel time reliability. Most drivers can accept an increase in their daily travel times, as long as it is consistent. Problems arise when drivers experience unexpected peaks in their travel times. As long as increased travel times are consistent, drivers can 
plan for the extra time needed to complete their commute. However, frustration is generated when the travel time varies too much day to day to reliably plan a commute.

A large-scale measure was developed as part of the Federal Highway Administration's Mobility Monitoring Program to quantify the reliability of travel times through a particular corridor. The buffer index is defined as the extra time (buffer) most travelers add to their average travel time when planning trips. For example, a buffer index of 40 percent means that a traveler should budget an additional 8-minute buffer for a 20-minute average peak travel time to ensure on-time arrival most of the time (95 percent in this report) (11)." The buffer index is the difference between the $50^{\text {th }}$ percentile travel time and the $95^{\text {th }}$ percentile travel time for a particular corridor. A corridor with very consistent times would have a low buffer index, while highly variable travel times would result in a high buffer index. This large-scale measure is eminently applicable to situations where a lot of data, taken over a long period, is available. Several concerns limit its usefulness for work zone application, however. The most pressing concern is that if the buffer index is used as the sole indicator of work zone mobility impacts, a skewed vision of operations could be formed if the work zone buffer index is lower than the buffer index of the freeway before implementation. The sketch in Figure 4 illustrates the example. 


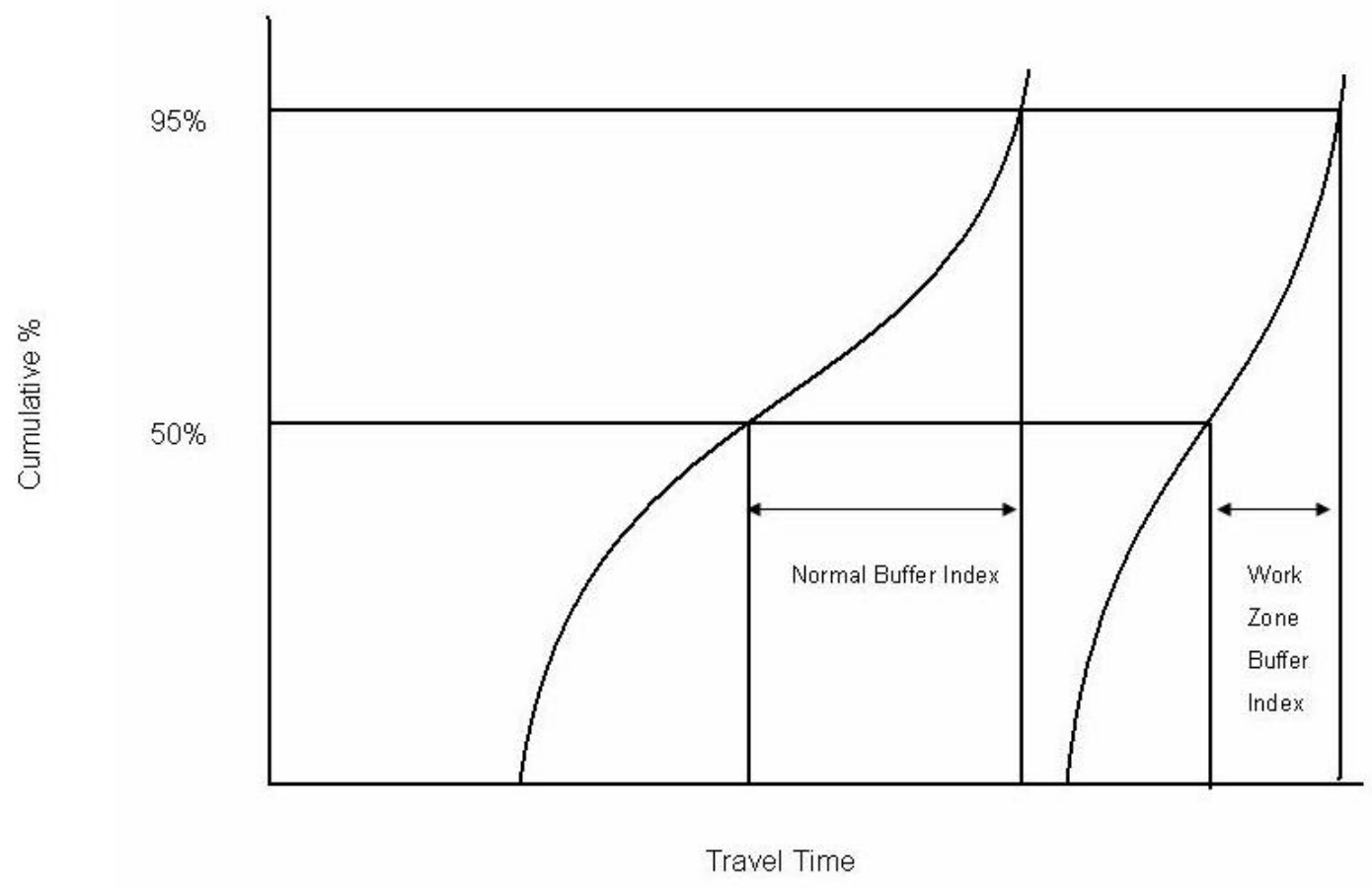

Figure 4: Buffer Index Example

As shown in the example, the buffer index for the work zone is smaller than the normal buffer index, but the overall travel times for the work zone are much higher. This would be caused by the reduced variation in delay due to the work zone; instead of some people being slowed down by the various conditions normally present on the roadway, everyone is delayed by the work zone. If the buffer index is the only performance measure used, then the conclusion would be mistakenly drawn that the work zone actually improved mobility on the roadway. Obviously, this is not the case, because the travel times through the work zone in this case are much higher than the travel times under normal conditions. The use of multiple measures will alleviate this concern; if both average travel times and the buffer index are used, then it will be obvious that the work zone is increasing the time necessary to travel through the work zone. 
Measuring the buffer index indicates the reliability of travel times through the work zone. By collecting travel time data only in the work zone, these amalgamated performance measures can be generated, and used to improve current and future implementation strategies.

Delays

The travel times can also be used to calculate delay-based performance measures. Delay measures are a subset of travel time measures; delay can be defined as the amount the travel time is increased. In this thesis, delay is defined as the difference between the baseline, expected travel time (travel time at the posted speed) and the observed travel time. Delay can be measured as delay per delayed vehicle. At this level, delay can be also be measured as the total delay for the facility, or the corridor, or the network. At the amalgamated level, the total delay through the work zone is normalized by dividing by the vehicle miles traveled. This allows for comparisons of work zones of different lengths, and/or different volume characteristics. Using this measure, the delay caused by two distinct work zones can be compared. Delay-based performance measures are a valuable, intuitive measure of the time-related impacts of decisions made in the work zone. They are easily transformed into cost-based performance measures, and some, such as average delay per delayed vehicle, have the potential to be easily understood by the public.

\section{Volumes}

Maintaining flow rates through a work zone is of paramount importance, because of the limitations imposed on the freeway by the implementation of the work zone. Because volume is such a simple metric, there is a plethora of ways to measure the number of vehicles that pass a given point. 
Most are basic measures of the number of vehicles traveling through the work zone, either from a temporal perspective (flow rate, measured in vehicles per hour) or a geometric perspective (volume per lane mile of work zone exposure). Vehicle miles traveled is a measure of the number of vehicles in the work zone, and can be used to normalize for work zones of different lengths. The volume counts are also a useful measure to compare with other measures, to ascertain the true meaning of the observed conditions. For example, an observed increase in the average delay per vehicle under normal conditions, coupled with a drastic increase in traffic, would reveal the true cause of the increased delays, which would simply be increased congestion due to increased volumes, as opposed to an increase caused by work zone activity.

\section{Capacities}

Measuring capacity as an indicator of performance in a work zone is typically done in the planning stages. The relationship between flow rate and capacity, the volume-to-capacity $(\mathrm{v} / \mathrm{c})$ ratio, is one of the best indicators of possible mobility problems. A straightforward large-scale measurement of volume (vehicles per hour) might not account for variations in work zone implementation. Normalizing this measure by vehicle miles traveled through the work zone (a measure of exposure), can more fully describe the impacts of the work zone. The length of time a vehicle is exposed to the work zone, measured in terms of the length of that work zone, is a very important factor in the impact of a work zone. Intuitively, the longer a vehicle is exposed, the more impact the work zone will have on the vehicle's mobility. This measurement will be used to normalize the volumes observed at work zones with different configurations, allowing a truer comparison of volume conditions. Vehicle miles traveled can also be used to normalize other performance measures, allowing easier comparisons between work zones. 


\section{Densities}

Large-scale volumes can also be measured in terms of densities. Density, usually given in terms of vehicles per mile per lane, can be difficult to measure directly. Average density is the simplest measure of density; it can also be used in conjunction with the Level of Service to determine the overall performance of the work zone.

Queues

Queues are another easily measured, readily apparent effect of congestion. As congestion increases and oversaturated conditions take effect on a freeway, queues form as vehicles slow down. Freeway queues don't necessarily bring traffic to a complete stop; speeds of approximately 20 miles an hour or below are typically enough for queuing conditions to be observed. At the small-scale level, queue length can be measured by the length of the queue in terms of individual vehicles; a 20-passenger vehicle queue, for example. At the large-scale level, the average queue length is typically measured in miles. As discussed in a previous chapter, most agencies have set an arbitrary queue length threshold that must not be exceeded. This threshold is typically in the 1-2 mile range. The large-scale measures need little modification to be adapted into amalgamated, work zone-specific measures, aside from basing the measures solely on data collected in the work zone. The average queue length observed in the work zone should be monitored to ensure that the queue length is not exceeding the threshold on a regular basis. When queues are observed frequently, it is an indication that something is wrong with the work zone. The occurrence of excessive queue lengths should also be monitored. Again, excessive queue lengths should not occur if the work zone is properly implemented. Table 3 summarizes the performance measures outlined in this chapter. The matrix in Table 4 matches the treatment strategies with their most descriptive performance measures. 
Table 3: Summary Table of Performance Measures

\begin{tabular}{|c|c|c|c|}
\hline & Small-Scale & Amalgamated & Large-Scale \\
\hline \multirow{5}{*}{ Speed } & Individual Speed & Average Speed & Average Speed \\
\hline & Point Speeds & 85th Percentile Speed & $\begin{array}{l}\text { 85th Percentile } \\
\text { Speed }\end{array}$ \\
\hline & & Speed Variance & Speed Differentials \\
\hline & & $\begin{array}{l}\text { Percentage of VMT Experiencing Lowered } \\
\text { Speeds (less than } 50 \mathrm{mph} \text { ) }\end{array}$ & \\
\hline & & Speed Profiles & \\
\hline \multirow{4}{*}{$\begin{array}{l}\text { Travel } \\
\text { Time }\end{array}$} & $\begin{array}{l}\text { Individual Travel } \\
\text { Time }\end{array}$ & Average Travel Time Through Work Zone & $\begin{array}{l}\text { Average Travel } \\
\text { Time for Freeway }\end{array}$ \\
\hline & $\begin{array}{l}\text { Individual Travel } \\
\text { Time Reliability }\end{array}$ & $\begin{array}{c}\text { Number of Analysis Periods of Excessive } \\
\text { Travel Time ( } 20 \% \text { increase) }\end{array}$ & Travel Time Index \\
\hline & $\begin{array}{l}\text { Excessive Travel } \\
\text { Time }\end{array}$ & $\begin{array}{l}\text { Percentage of VMT Experiencing } \\
\text { Excessive Travel Time }\end{array}$ & $\begin{array}{l}\text { Travel Time } \\
\text { Reliability }\end{array}$ \\
\hline & & Buffer Index & \\
\hline \multirow{4}{*}{ Delay } & Delay per vehicle & Total Delay per VMT & Total Delay \\
\hline & & $\begin{array}{l}\text { Number of Analysis Periods of Delay } \\
\text { (20\% increase in Travel Time) }\end{array}$ & Buffer Index \\
\hline & & Percentage of VMT Experiencing Delay & \\
\hline & & Length of Consecutive Delay Periods & \\
\hline \multirow{4}{*}{ Volume } & Point Volume & Work Zone Volume & Corridor Volume \\
\hline & Headways & Occupancy & Occupancy \\
\hline & & Volume per lane per mile of exposure & $\begin{array}{l}\text { Volume per lane } \\
\text { per mile }\end{array}$ \\
\hline & & Vehicle Miles Traveled & Flow Rate \\
\hline \multirow[t]{2}{*}{ Capacity } & $\mathrm{N} / \mathrm{A}$ & Percent Change in Volume/Capacity Ratio & $\begin{array}{c}\text { Volume/Capacity } \\
\text { Ratio } \\
\end{array}$ \\
\hline & & Change in Capacity & Capacity \\
\hline \multirow{3}{*}{ Density } & $\mathrm{N} / \mathrm{A}$ & Average Density & Average Density \\
\hline & & $\begin{array}{c}\text { Number of Analysis Periods of Excessive } \\
\text { Density (over } 35 \text { pvpmpl) }\end{array}$ & \\
\hline & & $\begin{array}{l}\text { Percentage of VMT Experiencing } \\
\text { Excessive Density }\end{array}$ & \\
\hline \multirow{3}{*}{ Queue } & $\begin{array}{l}\text { Number of Vehicles } \\
\text { in Queue }\end{array}$ & Average Queue Length in Work Zone & $\begin{array}{l}\text { Average Queue } \\
\text { Length }\end{array}$ \\
\hline & & Instances of Excessive Queue Length & $\begin{array}{l}\text { Queue Length } \\
\text { Reliability }\end{array}$ \\
\hline & & Recurrence of Queue Length & \\
\hline
\end{tabular}


Table 4: Performance Measure/Treatment Matrix

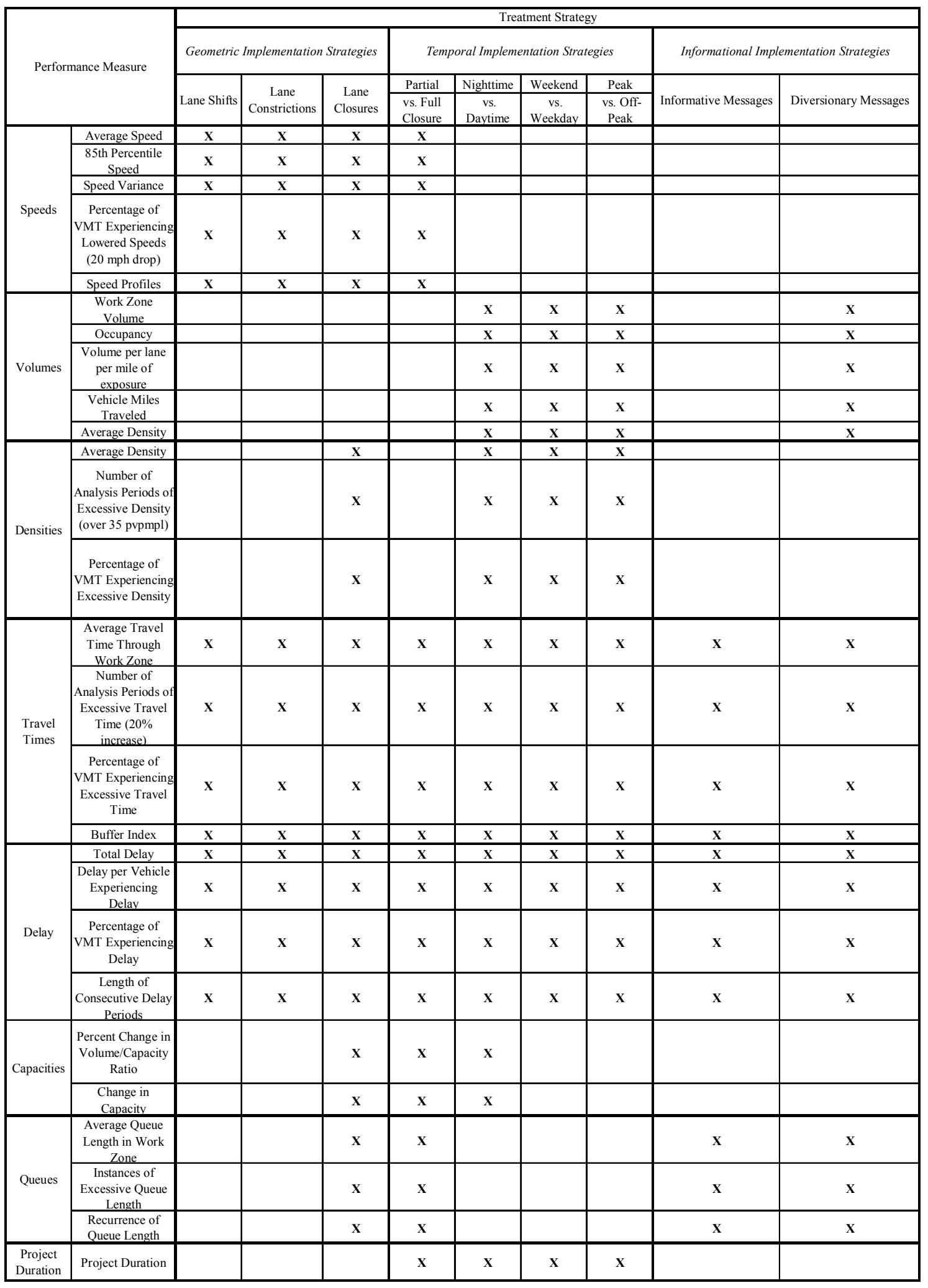




\section{Performance Measure/Treatment Matrix}

Initially, the matrix may appear to recommend an excessive number of performance measures for each treatment, with a high amount of data collection needed to calculate all of the measures. In actuality, many of the performance measures can be generated from the same data. For example, the average speed, $85^{\text {th }}$ percentile speed, speed differentials, and speed profiles can all be generated using the same collected speeds. Each of these speed measurements gives different information about the mobility through the work zone; aggregated, they fully depict the speed-related conditions within the work zone. Practitioners have leeway when choosing which performance measures to utilize. They are encouraged to choose the performance measures compatible with the goals set by their agency.

Additionally, the performance measures recommended in the matrix are not meant to be the exclusive measures used for the particular treatment. The matrix matches performance measures to the major impacts of treatments. Just because a particular treatment impacts speeds more than volumes does not mean that only the speed impacts should be measured, while excluding the volumetric measures. It just means that at the very least the work zone's impact on the speeds observed on the facility should be monitored. Practitioners are free to choose the performance measures they are concerned with; the matrix is a guide for which performance measures should be used. The use of as many performance measures as are reasonable is encouraged, in order to fully understand the complex impacts of a work zone on an urban freeway. As more performance measures are used, a clearer representation of mobility through the work zone is created. Through the use of these recommended amalgamated performance measures, the mobility in a single work zone can be monitored more effectively, and the mobility of several work zones can be compared. By using amalgamated measures, work zones utilizing different configurations, project durations, and implementation strategies can be easily compared to improve work zone performance in the future. 


\section{Revised Decision-Making Process}

The Performance Measure/Treatment Matrix can be a valuable tool for determining which performance measure will best describe the mobility impacts of the various work zone implementations, but without context, the matrix does not realize its full potential. The matrix needs to be incorporated into a systematic decision-making process. Agencies typically have processes already formulated, albeit informally, to make work zone related decisions, but these existing processes have three major deficiencies. The typical processes currently used:

- Employ the same performance measures for each work zone implementation;

- Rely on too few performance measures throughout the process; and

- Lack a feedback mechanism to incorporate the results of implemented work zones on future implementations.

As discussed in previous chapters, different work zone implementation strategies impact the mobility of an urban freeway in different ways. If an agency exclusively uses the same measures as the metric of performance for each work zone implementation strategy, some important mobility impacts will be overlooked, and perhaps not considered during the decision-making process. Practitioners need to ensure that the performance measures used as a basis for decision making are relevant to the work zone implementation strategies employed. The matrix discussed in the previous chapter can be used as a tool to find the correct performance measures.

Relying on too few performance measures to determine the mobility impacts of an implemented work zone is another flaw in the commonly used processes currently in use by various agencies. In many agencies, data collection and analysis limitations constrain the number of performance measures available to decision makers. Because of the changes to the roadway environment created by a work zone, multiple performance measures are needed to completely comprehend the mobility impacts. The use of 
multiple performance measures leads to a better understanding of work zone mobility impacts, which in turn leads to better decisions with respect to this mobility.

The lack of a feedback mechanism in the traditional decision-making processes prevents work zone implementation strategies from reaching their full potential. By evaluating work zones after the completion of the project, and comparing the work zone to other similar work zones, standards for implementation strategies can be improved to further mitigate the mobility impacts. By evaluating the impacts of a work zone after the fact, agencies may become aware of mobility impacts that were not readily apparent during the project. The reasons behind these impacts can then be determined, and the information gleaned from the post-completion analysis can be used to improve future work zone implementations. Once the work zones have been analyzed to determine what impacts were observed, and which impacts were unique to a specific work zone feature, more feedback is returned to the process, further improving implementation techniques and strategies. The measures used to evaluate the performance of the completed work zone should be the same measures used when the work zone was active. The measures should also reflect the goals of the agency; using them for evaluation of the work zone before, during, and after implementation should result in the progress toward meeting the goals. Addressing these three main deficiencies in the current processes was the purpose of creating an improved process, shown in Figure 5. 


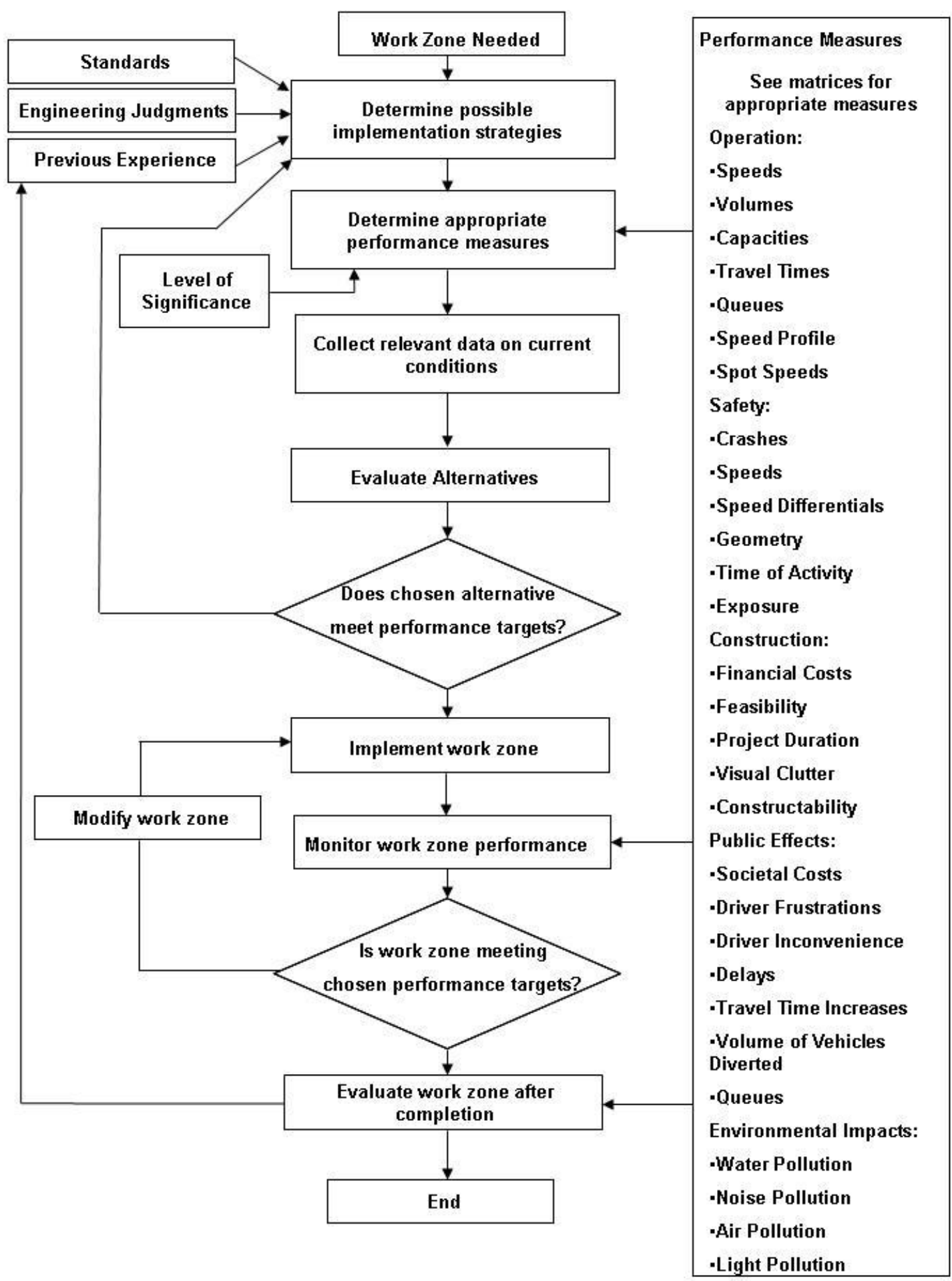

Figure 5: New Decision-Making Process

(See Table 4 for Performance Measure/Treatment Matrix) 
The process starts with the assumption that a work zone is needed, and the objective of the project is already understood. The level of significance of the work zone project determines how much performance monitoring is necessary. A large scale, long term project, such as reconstructing an urban freeway, requires careful monitoring of operations to ensure the work zone is impacting the operation of the freeway as little as possible. Different agencies define project significance differently. The simplest definition of a significant project, according to the FHWA (12) is one that:

- Is within the boundaries of a designated Transportation Management Area;

- Occupies a location for three days; and

- Has intermittent or continuous lane closures.

These significant projects are the ones that need to be monitored, using the appropriate performance measures taken from the matrix. These performance measures are then used to inform the decisions made throughout the rest of the process.

Based on existing conditions, and the type of activity necessary to meet the objectives of the work zone, various treatment configurations can be formulated. The alternative work zone traffic control plans should incorporate variations of several possible decisions to be made. The number of alternatives created depends on the feasibility of creating multiple alternatives and the decisions to be made about the work zone. The alternatives should be formulated using three main influences:

- $\quad$ Agency standards;

- $\quad$ Engineering judgments; and

- Previous experience.

Every agency has standard procedures and plans for creating a work zone. These standards should be followed when creating traffic control plans to ensure compliance. When the standards do not sufficiently mitigate the mobility impacts anticipated, 
engineering judgment should be used to modify the plans to improve performance. Previous experience should also be utilized as an adjunct to engineering judgment. The previous experience can be gleaned from both qualitative and quantitative assessments of prior work zones. Qualitative information is commonly a part of the current processes, but the use of quantitative measures as feedback to be incorporated back into the design phase of a work zone implementation is one of the improvements the new process is based on.

Once the appropriate performance measures are chosen, data is needed to determine baseline conditions on the facility. The data collected on the facility prior to the implementation of the work zone are used for comparison to determine the impacts of the work zone.

Once the multiple alternatives have been created, they need to be analyzed using the amalgamated performance measures deemed appropriate earlier in the process. At this stage of the process, the performance measures are only measuring the predicted impacts, so the results of this analysis may not sync perfectly with the impacts observed in the real world after implementation of the work zone. Once the alternatives have been analyzed to predict their mobility impacts, the practitioner must decide whether the alternatives meet the goals described by the performance measures. If at least one of the proposed alternatives meets the goals set forth previously, then the process can move to the next step.

Based on the evaluation, the work zone alternative with the least undesirable impacts should be chosen for implementation. Once the work zone is active and in place, performance measures are used to monitor conditions within the work zone. Depending on the data collection techniques, these performance measures can be used to alert agencies to traffic problems within the work zone practically in real time.

If possible, data collected in a work zone, should be used to monitor performance to ensure there are no excessive impacts on motorists. When excessive impacts are observed in the performance measures, the agency should take steps to correct the issue and redeploy the work zone with the necessary adjustments. Addressing these issues as 
they occur can result in a safer work zone with more mobility, leading to benefits including fewer crashes, less delay, a safer environment for workers in the work zone, and less driver frustration.

The data collected in the active work zone should be used to evaluate the work zone after completion. Reevaluating the observed conditions from a distance, looking at the overall project, can lead to valuable insights that can be used to improve future work zone implementations. By examining conditions that led to problems in work zones, what steps were taken to correct these problems, and how well the corrections addressed the problem, work zone implementations can be improved, and the overall goals of the agency can come closer to reality.

The lessons learned in the evaluation phase of the process are then used as feedback into the previous experience used to initially create implementation alternatives. The improvements from each work zone will be incremental, and not immediately apparent, but as feedback becomes more standardized and more data is gathered about various implementation strategies, agencies will be able to improve their work zone strategies dramatically. 
This new process was created to address the three main deficiencies observed in the current processes for making decisions in work zones on urban freeways. The use of the same performance measures for different work zone implementation strategies was addressed through the use of the performance measures matrix, specifically the Operational Performance Measures Matrix presented earlier in this chapter. The reliance on a limited number of performance measures, which may or may not be sufficient to create a complete description of conditions within the work zone, was addressed through the recommendation to use more performance measures. A single performance measure can be misleading; using multiple performance measures describing different aspects of work zone impacts can more completely describe the conditions within the work zone and improve decision making. Feedback based on a post-completion analysis of work zone impacts can also be a tool for improving decisions. By including feedback as an explicit step in the revised process, along with comparisons to other similar work zones, it is expected that trends in work zone impacts will become more readily apparent, and easier to use as a basis for decisions. 


\section{CHAPTER IV}

\section{APPLICATION OF REVISED PROCESS AND ISSUES THEREIN}

The measures proposed in this thesis would be vapid theoretical constructs without somehow validating their usefulness for real world application. To validate the application of these performance measures in an actual work zone, the measures were applied to data gathered in a work zone on Interstate Highway 35, north of Hillsboro, Texas. The data was collected by the Texas Department of Texas's Waco District, using mobile ITS equipment on trailers. The project encompassed a variety of improvements and modifications, including altering the main-lane centerline, adding bridges, and adding exit ramps. There were numerous lane-switches, freeway closures, lane closures, and forced detours, depending on the location of work. The complexity of the work zone activity hinders easy analysis of the mobility impacts of the work zone. The area of interest, and therefore the focus of the data collection, data monitoring, and data analysis, was the congestion created by the construction.

The ITS equipment used to collect the data was a Wavetronix brand side-firing microwave system mounted atop a 25 foot telescoping pole (14). The non-invasive ITS trailers were placed in the clear zone along the shoulder of the highway. The Wavetronix microwave radar was used to collect aggregate measures of volume, speed, and occupancy for each lane every minute (14). The one minute aggregated time periods were then further collected into 15 minute analysis periods, to facilitate data analysis. Any obviously erroneous data, such as collection periods with unreasonably high average speeds and volume and occupancy values of zero, were expunged from the data set to preclude misleading conclusions about the impact of the work zone on the traffic characteristics on the roadway.

The approximate limits of the work zone in the study area (which actually incorporated two different projects) are shown in Figure 6 (13). The data collection trailers are also numbered in the figure. The uncircled icons are the portable changeable message signs, used to disseminate traffic information to drivers. 


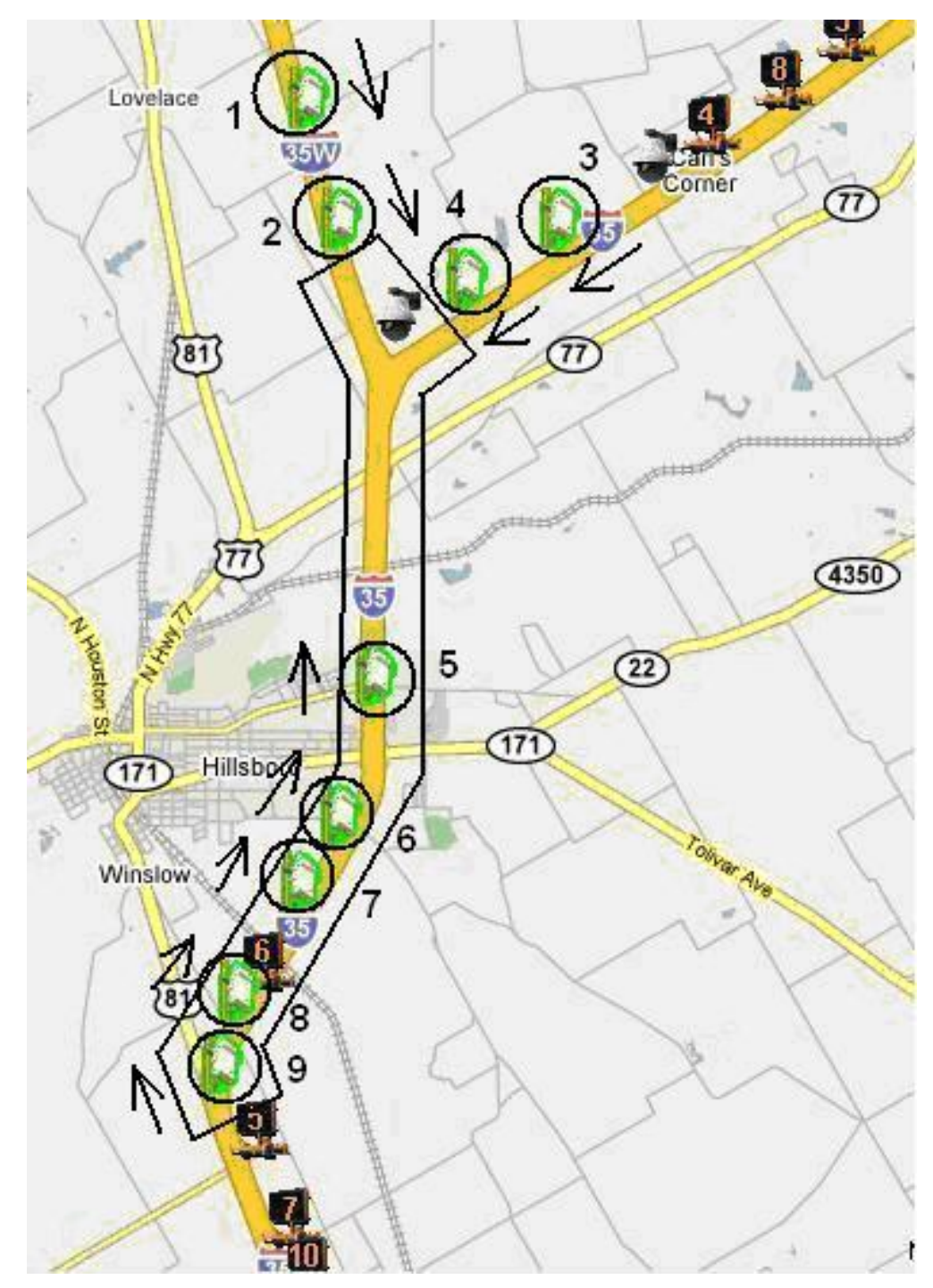

Figure 6: Extents of Work Zone

The analysis focused on three easily collected, easily analyzed performance measures that were still descriptive of mobility through the work zone, and indicative of other aspects that they did not directly measure. The three measures chosen were based around delay. This aspect of mobility was chosen as the focus because it incorporates most of the other aspects of mobility within one metric. All aspects of mobility are related - increased volumes and lowered capacities lead to an increase in densities, which result in lowered speeds, increased travel times, increased delays, less reliability 
in travel times, and longer queue lengths, for example. With the right performance measures, most of the relevant aspects of mobility in the work zone can be monitored. The three delay-based performance measures chosen for the analysis were:

- $\quad$ Change in total delay;

- $\quad$ Change in delay per delayed vehicle; and

- $\quad$ Change in buffer index.

The change in each measure is computed from the baseline values established from traffic data predating the implementation of the work zone. These measures were chosen because of their inclusion of multiple aspects, and their potential to describe other aspects not directly measured. Because delay is measured as an increase in travel time above an acceptable threshold, information about travel times through the work zone is implied in the measures. Implicit information about the speeds is available, because travel time is related to speed through the area. Volumes are not directly measured through the delay itself, but the change in delay per delayed vehicle accounts for any delay caused by an increase in traffic volumes. When compared to the change in total delay, inferences can be drawn as to whether an increase in traffic was to blame the observed delays as opposed to the work zone. If total delay increases, yet individual delays are stable, the increase in total delay was due to an increase in traffic, and not the work zone itself. The change in total delay describes the overall impact of the work zone on the entire traffic stream. It describes any slowdowns possibly caused by the work zone, or other influences such as increased traffic volumes. The change in delay per delayed vehicle describes the delay experienced by a typical motorist. By dividing the total delay among the total volume of delayed vehicles during the period, volumes are accounted for in the performance measures. The change in buffer index indicates the impact the work zone had on the reliability of travel times through the work zone. Using these three performance measures will allow for enough detail to determine how much impact a work zone had on a particular freeway, and whether the decisions made 
were beneficial or detrimental. These measures are not comprehensive, nor meant to be the absolute set of performance measures to use in every analysis. As previously stated, all aspects of mobility are interrelated, and other measures could be chosen to describe the impacts. The delay-based performance measures offer an easily collected and analyzed set of measures that incorporate most of the aspects of mobility, resulting in a suite of measures that can easily be incorporated by engineers to assess their decisions in work zones.

\section{Goals of Analysis}

The first goal of this data analysis was to apply the new method of analyzing different decisions made throughout the lifespan of a work zone, with a focus on posthoc analysis. The second goal was to examine the issues related to using the new process, especially with regard to the use of multiple performance measures. Figure 7 shows how the analysis fits into the revised process. 


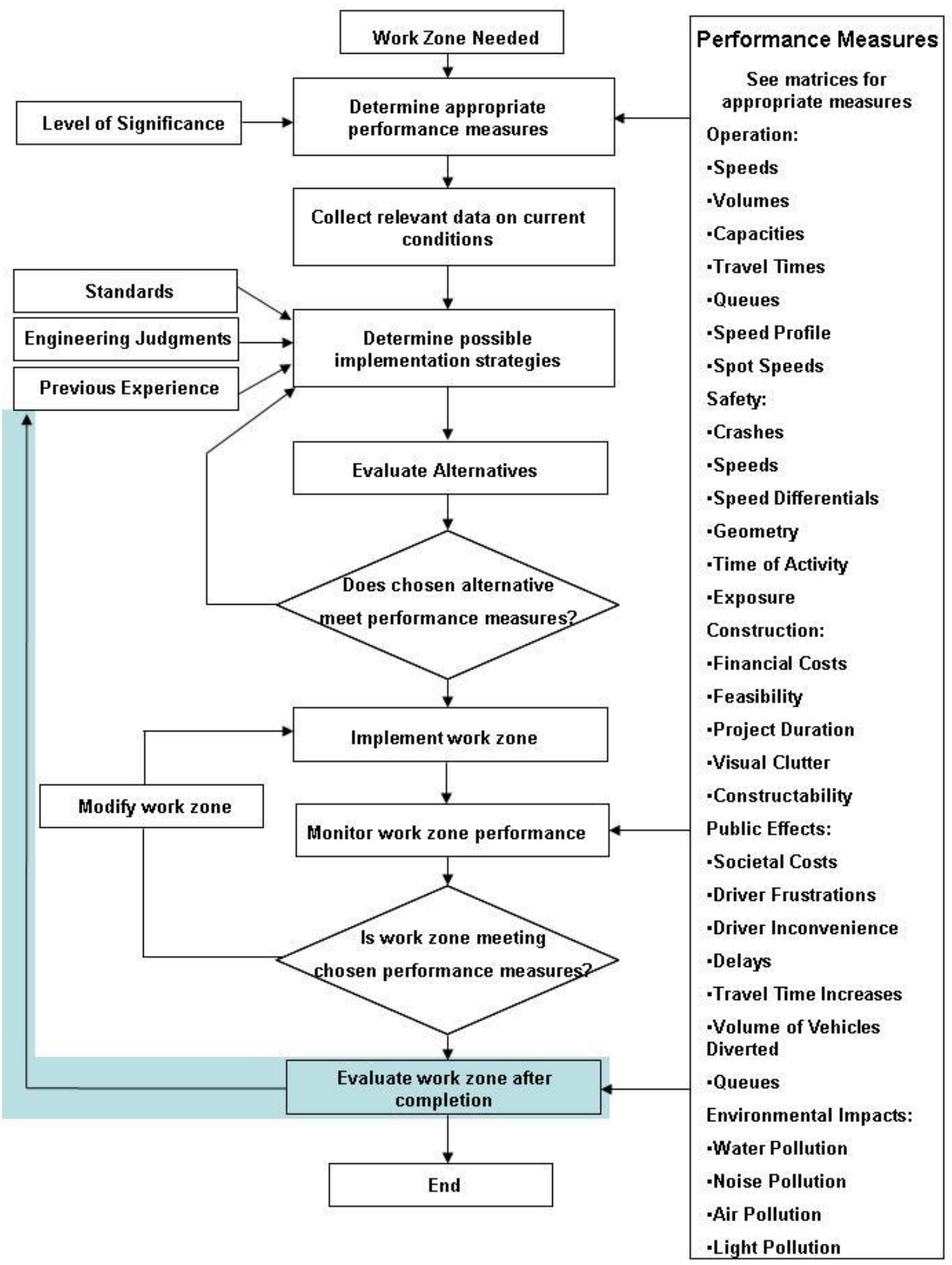

Figure 7: Relevant Portion of Process 
Traffic stream data were collected continuously throughout the lifespan of the I-35 project in Hillsboro. The data sets considered in this analysis were collected during the months of November 2006 and June 2007. These months were chosen as the focus of the analysis because they represented periods of heavy work zone activity (and resulting lane closures, diversions, etc.) and relatively light work zone activity, respectively. The two data sets were used in conjunction with the baseline data collected in the months prior to the start of Hillsboro work zone activity (October 2006) to assess the impacts of the decisions made in the work zone.

Issues with Data

Because the data were collected in a highly variable, real world environment, data issues were inevitable. The nature of the microwave data collectors caused some data to be erroneously recorded, such as a reading of zero volume, zero occupancy, and a measured speed. Data entries of zero volume, zero occupancy, and a measured speed were obviously inaccurate, because a "phantom," ephemeral vehicle, unable to be recorded by the sensors, could not have a valid, measurable speed. Data entries with zero volume, zero occupancy, and a recorded speed were expunged from the data set to avoid skewing caused by incorrectly recorded data.

Another issue with the data was a large amount of missing data, especially in the June 2007 set. Frequently, the detectors would skip a minute-long data collection period. The June 2007 data created more of a problem, because it was missing sizeable chunks of data. Data was missing for approximately 100 hours during the month of June. Because this was the only other data set available to contrast to the November 2006 data set, the missing data was simply omitted from the analysis.

Yet another major issue with the data set arose when detailed information about work activity was not available. Without knowing specifically what activities were undertaken at which specific times, detailed analysis of the mobility impacts of specific 
decisions was not possible. Instead, an overall analysis of month-long periods was undertaken, to illustrate possible uses and problems with the revised process.

The data was aggregated into 15 minute analysis periods, and the one-minute data values were collected into 15 minute values. The data were aggregated into measures of:

- Total Volume;

- Equivalent Hourly Volume;

- Average Occupancy; and

- Average Speed.

Average speed was the only measure needed from these aggregations to compute the delay-based performance measures. The average speed for the analysis period was calculated as a weighted average, based on the number of vehicles counted during the analysis period and the average speed observed during the one-minute periods. These average speeds were then used to calculate the travel times, from which the performance measures could be calculated.

Once the analysis periods had been properly aligned for each lane, the travel times were calculated, using the half-distance method (16), shown below:

$$
\text { TravelTime }=\frac{1}{2}\left(\frac{d}{v_{u}}+\frac{d}{v_{d}}\right)
$$

Where:

- $d$ is the distance between the detectors;

- $v_{u}$ is the average speed at the upstream detector; and

- $v_{d}$ is the average speed at the downstream detector.

This method uses spot speeds from two locations to determine the travel time between the two locations. This method operates under the assumption that the vehicles 
travel half the distance between detectors at the upstream speed, and the other half at the downstream observed speed.

\section{Baseline Conditions}

Baseline data were established from traffic counts taken prior to the implementation of the work zone by Science Applications International Corporation (SAIC) (17). The data was collected using the same Wavetronix brand side-firing microwave system mounted on mobile trailers that collected data in the work zone (14). The system collected speed, volume, and occupancy data in the same manner as the work zone data, using the same methods used in the work zone. However, this data was not collected for consecutive locations, downstream from each other. One of the three baseline-data collecting trailers was positioned on each leg of the I-35 split. This complicated the assessment of baseline conditions, because the half-distance method could not be used to calculate the free-flow speed. Out of necessity, the free-flow speed was calculated from the average 15-minute period speeds from one detector location. The free-flow speed was calculated from this baseline data, according to the Highway Capacity Manual's specifications. Speeds measured under free-flow conditions (when traffic volumes were less than 1300 passenger cars per hour per lane) were averaged to determine the base free-flow speed for the facility. The standard travel time was based on the free flow speed. Delay was then calculated as any travel time above the travel time between the two detectors at free flow speed. Baseline values for three performance measures were calculated from travel time data:

- Total delay;

- Delay per delayed vehicle; and

- Buffer index. 
To assess the amount of delay to which individual vehicles were exposed, the total delay was distributed among all vehicles experiencing delay. The number of vehicles experiencing delay was found by summing the volumes observed during each analysis period where travel time was above the baseline travel time. The total delay was then divided amongst these vehicles to assess how long the average delay was for northbound motorists traveling through the work zone. Dividing the total delay among the total volume, rather than only those vehicles experiencing delay, would result in misleadingly low average delays. If all vehicles were included in this calculation, the total delay would be partially attributed to vehicles that, in reality, did not experience delay. The performance measures used to assess the baseline condition of the facility are tabulated in Table 5.

Table 5: Baseline Performance Measure Summary - October 2006

\begin{tabular}{|c|c|c|c|}
\hline Free-Flow Speed & Lane 1 & 68 & miles per hour \\
\hline $\begin{array}{c}\text { Free-Flow Travel Time Through } \\
\text { November 2006 Work Zone Configuration }\end{array}$ & Lane 1 & 65 & seconds \\
\hline $\begin{array}{c}\text { Free-Flow Travel Time Through } \\
\text { June 2007 Work Zone Configuration }\end{array}$ & Lane 1 & 87 & seconds \\
\hline
\end{tabular}

November 2006

In November 2006, the work zone became active. As part of the traffic management strategy described in earlier chapters, lane closures were occasionally necessary. The mitigation strategy employed by the agency consisted essentially of portable changeable message signs, wireless communicating with the microwave detectors in the area to determine when traffic through the work zone became congested. When congestion was detected in the area, messages advising motorists to utilize the alternate route through Hillsboro was displayed. When lanes were closed, the median lane was typically the lane closed. For this reason, the shoulder (outside) lane was the 
focus of the data analysis. Data was collected in the work zone throughout the month of November 2006. This data was analyzed to determine the buffer index, total delay, delay per vehicle, and overall condition of the roadway. When examining the decisions made in November 2006, it should be considered that the month of November is the month with the highest traffic volumes on the facility, due to the large amount of travel during the Thanksgiving season. Even though the average delay experienced by drivers when delay was present was high, the fact that only $11 \%$ of drivers during the peak traveling season on the facility experienced delay means that the work zone did not impact mobility as significantly as it would have without the mitigation measures taken by the department. Table 6 displays a summary of the performance measures used to assess the conditions on the roadway for the month of November 2006.

Table 6: Summary of November 2006 Performance Measures

\begin{tabular}{|c|c|c|}
\hline Average Travel Time & 62 & seconds \\
\hline 95th Percentile Travel Time & 78 & seconds \\
\hline Buffer Index & $26 \%$ & \\
\hline Total Delay & 20.2 & days \\
\hline Delay per delayed vehicle & 75 & seconds \\
\hline Maximum Observed Delay & 1157 & seconds \\
\hline$\%$ of vehicles delayed & $11 \%$ & \\
\hline
\end{tabular}

June 2007

June 2007 was chosen as the second analysis period because of the relatively "normal" amount of traffic. The month of June has no major traveling holidays, college semesters (typically a high generator of traffic in the area) are typically over, and there are no other major traffic generators affecting traffic. Despite the seemingly advantageous traffic characteristics when compared to November, June 2007's performance measures showed somewhat worse mobility conditions on the facility. 
Table 7 summarizes the performance measures used to assess the impact of the implemented work zone during the month of June 2007.

Table 7: Summary of June 2007 Performance Measures

\begin{tabular}{|l|l|l|}
\hline Average Travel Time & 100 & seconds \\
\hline 95th Percentile Travel Time & 209 & seconds \\
\hline Buffer Index & $109 \%$ & \\
\hline Total Delay & 25.9 & days \\
\hline Delay per delayed vehicle & 179 & seconds \\
\hline Maximum Observed Delay & 572 & seconds \\
\hline \% of Vehicles Delayed & $10 \%$ & \\
\hline
\end{tabular}

The differences in the performance measures observed in November 2006 and June 2007 illustrate the difficulties inherent in using multiple performance measures. While using multiple performance measures illustrates the conditions in a work zone more fully than using a single performance measure, they can sometimes give contradictory and misleading results. In the example illustrated by the Hillsboro data, the decisions made in November 2006 had much lower mobility impacts than the decisions made in June 2007. If the analysis was based solely on total delay, buffer index, and delay per vehicle delayed, then November 2006's decisions were clearly superior to the decisions made in June 2007, because all of these metrics were lower in November. However, when the maximum observed delay and percentage of vehicles delayed is taken into account, June 2007's decisions appear to be superior. In this case, using multiple performance measures caused the decisions' results to be somewhat obfuscated, it also illustrated what exactly was going on during these analysis periods. November 2006 had much less delay observed, but more vehicles were delayed, and the peak delays were more severe. June 2007 had fewer delayed vehicles and less severe peak delays, but there was more delay overall, spread more consistently among the 
traveling public. These results illustrate another great debate about mobility impacts - is it better to delay a few vehicles infrequently for a very long time, or is it more desirable to spread that delay among more vehicles over the duration of the work zone. This question must be answered individually by every decision maker.

Using a single performance measure allows for easy decisions - a comparison must be made between two measures to determine which is most desirable. A single measure could be just as misleading as a suite of multiple performance measures, as shown with the Hillsboro data. In order to make the most informed decisions possible, multiple performance measures should be utilized. When utilizing multiple performance measures, it is necessary to define the ultimate goals of the decisions made. Based on the ultimate goals, the appropriate performance measures can be chosen.

Applying the process to the Hillsboro data illustrated other difficulties with using data as a basis for decision making, especially the nature of the data involved. The Hillsboro data was as complete a data set as one could reasonably hope for, yet it was still missing thousands of data points, and was rife with incorrect readings. A data set will never be perfect, and this fact should be taken into account when choosing and using performance measures. Also, other factors that impact mobility are not reflected in the measures. For example, inclement weather conditions can adversely affect mobility, but are not reflected in any of the performance measures. Even with the best performance measures, other information must still be taken account when assessing decisions made. Quantitative performance measures are a very important component of the revised decision-making process, but engineering judgment and common sense are still necessary. 


\section{CHAPTER V}

\section{CONCLUSIONS AND RECOMMENDATIONS}

The concepts explored in this thesis, the ideas pursued, and the analysis performed led to several conclusions about the processes and measures used to plan, manage, and assess the impacts of a work zone implemented on an urban freeway. The main objectives of this thesis were twofold: to propose a process to relate work zone planning decisions and potential work zone performance measures, and to determine a set of performance measures that would enable comparison of the mobility impacts of various work zones.

\section{Conclusions}

One major focus of the thesis was the creation of an improved process for making work zone decisions, based on data, throughout the entire lifespan of a project, from design, to implementation, to post-completion analysis. The current processes in place are often lacking in three key areas. The current processes are lacking because, for the most part, they rely on the same performance measures for each type of work zone implementation, rely on too few performance measures to monitor and assess the impacts of the work zone, and lack a feedback mechanism to incorporate the results of completed work zones into the planning and monitoring of future work zones. The revised process presented was created with these problems in mind. The revised process is paired with a Treatment/Performance Measure Matrix, which recommends the appropriate performance measures, based on the most significant expected impacts of the chosen implementation strategies. The Matrix also recommends a suite of performance measures. By utilizing multiple performance measures, a more complete assessment of the impacts of the work zone can be created, leading to a better understanding of the impacts and their underlying causes. The feedback mechanism incorporated into the new process allows for a post-hoc analysis of a work zone, 
allowing the lessons learned from a particular implementation to be applied to future implementations, improving strategies and lessening the negative impacts of implementing a work zone on an urban freeway.

An important component of the new process is the performance measures utilized within. Creating performance measures that would adequately assess the complex impacts of a work zone on an urban freeway was the other major focus of the thesis. The selection of the appropriate performance measures to monitor the work zone is one of the most critical steps in the monitoring and assessment process. The measures chosen should reflect the goals of the agency, as well as the impacts of the expected impacts of the implementation plan chosen. The Treatment/Performance Measure Matrix lists a multitude of potential performance measures that can be applied to a work zone on an urban freeway facility to predict, monitor, and assess the mobility impacts. The measures in the Matrix can be applied to a variety of different work zones, with different traffic characteristics, implementation plans, configurations, and decisions.

Decisions made in a work zone affect all of the aspects involved. In some ways, making decisions in a work zone is like squeezing a balloon. Squeezing one side of the balloon (i.e. minimizing total delay by working only at night) causes the other side to inflate more (project durations and costs increasing). This balancing act is difficult, and must be accounted for when planning, implementing, and analyzing a work zone. The unintended consequences of decisions can be more easily quantified when using multiple performance measures, as suggested in the revised process. The data-based feedback loop also aids in determining these consequences, by using the results of previous implementations to improve future decisions. 


\section{Recommendations}

Based on the conclusions reached through this thesis, several recommendations can be made:

- Decision makers should base work zone-related decisions on quantitative data, as well as past experience and engineering judgment;

- Decisions should be made in the context of the new process, with different measures for different implementations, utilizing multiple measures to fully detail the impacts, and using post-hoc analysis to inform future decisions;

- The performance measures chosen should be utilized throughout the process, from planning to monitoring to analysis;

- The performance measures should be chosen with the goals of the agency and the probable impacts of the work zone in mind; and

- Performance measures should be tailored to the decisions made in the work zone.

The results of this thesis also point to many future research efforts that could further improve the monitoring of impacts a work zone. Among the possible areas that could be further explored are:

- Examining the effectiveness of other aspects of the process, including the planning and monitoring aspects;

- Creating and examining safety-based performance measures;

- Creating and examining construction-based performance measures;

- Creating and examining societal impact-based performance measures;

- Creating and examining environmental-based performance measures; and

- Apply the principles set forth in the new process to arterials, to determine whether it is still applicable. 


\section{REFERENCES}

1. A Policy on Geometric Design of Highways and Streets. American Association of State Highway and Transportation Officials, Washington, DC, 2004, $5^{\text {th }}$ Edition.

2. Abrams, C. M. and J. J. Wang. Planning and Scheduling Work Zone Traffic Control. Implementation User Guide FHWA-IP-81-6. FHWA, U.S. Department of Transportation, 1981.

3. Krammes, R.A., G.L. Ullman, G. B. Dresser, and N.R. Davis. Application of Analysis Tools to Evaluate the Travel Impacts of Highway Reconstruction with Emphasis on Microcomputer Applications. Publication FHWA-ED-89-023. FHWA, U.S. Department of Transportation, 1989.

4. Mahoney, Kevin M., Richard J. Porter, Douglas R. Taylor, Bohdan T. Kulakowski, and Gerald L. Ullman. Design of Construction Work Zones on High-Speed Highways. Report 581. National Cooperative Highway Research Program, Transportation Research Board, National Research Council, 2006.

5. Edara, Praveen. Estimation of Traffic Impacts at Work Zones: State of the Practice. Publication VTRC 06-R25. Virginia Transportation Research Council, Virginia Department of Transportation, 2006.

6. Maze, Tom, G. Burchett, and J. Hochstein. Synthesis of Procedures to Forecast and Monitor Work Zone Safety and Mobility Impacts. Midwest Transportation Consortium, the Center for Transportation Research and Education, November 2005. 
7. Hartmann, Thomas. Work Zone Performance Measure Survey Summary. Conducted for Texas Transportation Institute, College Station, TX, 2007.

8. Turner, Shawn, Rich Margiotta, and Tim Lomax. Monitoring Urban Freeways in 2003: Current Conditions and Trends from Archived Operations Data. Publication FHWAHOP-05-018. FHWA, U.S. Department of Transportation, 2004.

9. Texas Manual on Uniform Traffic Control Devices. Texas Department of Transportation, Austin, TX, 2006 Edition.

10. Zhang, Yunlong. "Introduction to Traffic Flow Characteristics." Presented at Texas A\&M University, College Station, TX, August 29, 2007.

11. Turner, Shawn, Rich Margiotta, and Tim Lomax. Monitoring Urban Freeways in 2003: Current Conditions and Trends from Archived Operations Data. Publication FHWAHOP-05-018. FHWA, US Department of Transportation, 2004.

12. Scriba, Tracy and Krista Jeannotte. Implementing the Rule on Work Zone Safety and Mobility. Publication FHWA-HOP-05-065. FHWA, U.S. Department of Transportation, September 2005.

13. “I-35 Work Zone in Hillsboro, Texas.” Texas Department of Transportation, Waco, Texas. http://www.wacoih35hillsboro1.com. Accessed October 25, 2007.

14. "Wavetronix- Smart Sensor." Wavetronix LLC, Lindon, UT. http://www.wavetronix.com/smartsensor/105. Accessed November 7, 2007. 
15. Klein, Lawrence A., Milton K. Mills, David R.P. Gibson. Traffic Detector Handbook: Third Edition. Publication FHWA-HRT-06-108. FHWA, U.S. Department of Transportation, 2006.

16. Zhang, Wang. Freeway Travel Time Estimation Based on Spot Speeds. Unpublished doctoral applied dissertation, Virginia Polytechnic Institute and State University, Blacksburg, VA. Retrieved October 15, 2007, from Virginia Polytechnic Institute and State University, Web site http://scholar.lib.vt.edu/theses/available/etd-06292006000823/unrestricted/Wang_Zhang_Dissertation_ETD_Copy_Ver_08_18_After_ETD_4t h_Review.pdf

17. SAIC: From Science to Solutions. Science Applications International Corporation, San Diego, California. http://www.saic.com/tools/contact.html. Accessed December 11, 2007. 


\section{APPENDIX}

\section{OTHER POTENTIAL PERFORMANCE MEASURES}

This thesis focused on operational performance measures to assess the impacts of a work zone on an urban freeway facility. Because there is a nearly infinite number of performance measures that can be used to assess the operational impacts of a work zone, the decision makers must decide what the ultimate goals of the work zone are, and choose measures that are descriptive of that goal. However, operations are not the only area of interest impacted by the implementation of work zone. Some of the other measurable impacts of implementing a work zone are observed in the areas of:

- Safety;

- Construction Issues;

- $\quad$ Public Effects; and

- $\quad$ Environmental Impacts.

The following list incorporates many possible performance measures that can be used to determine the impacts of the work zone in these various areas. The list is not intended to be comprehensive or authoritative; it is meant to stimulate the development of appropriate performance measures that fit the characteristics of a particular work zone implementation and the goals of the responsible agency.

Safety

- Crash rates upstream from work zone

- Crash rates in work zone

- Crash rates downstream from work zone

- $\quad$ Location of all crashes in area

- Crash rates on alternate routes around work zone

- Weaving maneuvers upstream of work zone 
- Weaving maneuvers in work zone

- Weaving maneuvers in work zone area prior to implementation

- Number of "Property Damage Only" accidents upstream of work zone

- Number of "Property Damage Only" accidents in work zone

- Number of "Property Damage Only" accidents downstream of work zone

- Number of "Property Damage Only" accidents prior to implementation of work zone

- Change in number of "Property Damage Only" accidents due to work zone

- Location of "Property Damage Only" accidents upstream of work zone

- Location of "Property Damage Only" accidents in work zone

- Location of "Property Damage Only" accidents downstream of work zone

- Location of "Property Damage Only" accidents prior to implementation of work zone

- Change in location of "Property Damage Only" accidents due to work zone

- Rate of "Property Damage Only" accidents upstream of work zone

- Rate of "Property Damage Only" accidents in work zone

- Rate of "Property Damage Only" accidents downstream of work zone

- Rate of "Property Damage Only" accidents prior to implementation of work zone

- Change in Rate of "Property Damage Only" accidents due to work zone

- Number of injury accidents upstream of work zone

- Number of injury accidents in work zone

- Number of injury accidents downstream of work zone

- Number of injury accidents prior to implementation of work zone

- Change in number of injury accidents due to work zone

- Location of injury accidents upstream of work zone 
- Location of injury accidents in work zone

- Location of injury accidents downstream of work zone

- Location of injury accidents prior to implementation of work zone

- Change in location of injury accidents due to work zone

- Rate of injury accidents in work zone

- Rate of injury accidents downstream of work zone

- Rate of injury accidents prior to implementation of work zone

- Change in Rate of injury accidents due to work zone

- Number of fatal accidents upstream of work zone

- Number of fatal accidents in work zone

- Number of fatal accidents downstream of work zone

- Number of fatal accidents prior to implementation of work zone

- Change in number of fatal accidents due to work zone

- Location of fatal accidents upstream of work zone

- Location of fatal accidents in work zone

- Location of fatal accidents downstream of work zone

- Location of fatal accidents prior to implementation of work zone

- Change in location of fatal accidents due to work zone

- Rate of fatal accidents in work zone

- Rate of fatal accidents downstream of work zone

- Rate of fatal accidents prior to implementation of work zone

- Change in Rate of fatal accidents due to work zone

- Same accident data as above, but for alternate routes

- Factors in all crashes that could be attributed to work zone

- Factors in all crashes that can not be attributed to work zone

- Presence of positive separation for workers and traffic (concrete barriers) 


\section{Construction}

- $\quad$ Financial costs of the project

- Difference in cost between night work vs. day work

- Difference in cost between working during peak vs. off-peak

- Difference in cost between closing one lane at a time vs. total freeway closure

- Difference in cost between continuous vs. intermittent work

- Feasibility of implementation plan

- Manpower needed for implementation (and associated costs)

- Machinery needed for implementation (and associated costs)

- $\quad$ Project duration (night work vs. day work)

- $\quad$ Project duration (peak vs. off-peak)

- $\quad$ Project duration (single lane closure vs. total freeway closure)

- $\quad$ Project duration (continuous vs. intermittent work)

- Visual clutter (hampers drivers)

Public Effects

- Number of drivers exposed to construction activity

- Number of drivers exposed to extra delays due to construction activity

- Total man-hours workers were exposed to traffic

- $\quad$ Driver frustration caused by work zone

- Number of drivers inconvenienced by the work zone

- Costs of total delays

- Costs of delays per vehicle

- Costs of additional fuel due to congestion

- Cost of lost time

- Increases in travel time during peak period

- Increases in travel time during off-peak period 
- Increases in travel time during lane closures

- Increases in travel time during active work periods

- Number of vehicles diverted

- Amount of time spent in queues, total

- Amount of time spent in queue, per vehicle

- $\quad$ Recurrence of queues

- $\quad$ Reliability of queues

- Driver expectancy

- Effectiveness of information system for informing drivers of conditions within work zone

Environmental Impacts

- Increase in water pollution caused by runoff from construction site

- Increase in noise pollution caused by construction equipment

- Increase in noise pollution caused by increased congestion

- Increase in air pollution caused by construction equipment

- Increase in air pollution caused by increased congestion

- Increase in particulate matter caused by increased congestion

- Increase in particulate matter caused by construction activity

- Increase in light pollution caused by night-work 


\section{VITA}

Name: $\quad$ Thomas Wayne Hartmann

Address: $\quad$ Kimley-Horn and Associates

12700 Park Central Drive

Suite 1800

Dallas, TX 75251-1516

Email Address: thomas.w.hartmann@gmail.com

Education: $\quad$ B.S., Civil Engineering, Texas A\&M University, 2006

M.S., Civil Engineering, Texas A\&M University, 2008 